\title{
Nickel-based 3D Electrocatalyst Layers for Production of Hydrogen by Water Electrolysis in an Acidic Medium
}

\author{
ZIAD BOU-SALEH \\ Department of Chemical Engineering \\ McGill University, Montreal
}

May 2008

A thesis submitted to McGill University in partial fulfillment of the requirements for the degree of Master of Engineering

(C) Ziad Bou-Saleh 2008 
Library and

Archives Canada

Published Heritage

Branch

395 Wellington Street

Ottawa ON K1A 0N4

Canada
Bibliothèque et

Archives Canada

Direction du

Patrimoine de l'édition

395 , rue Wellington

Ottawa ON K1A ON4

Canada

Your file Votre référence

ISBN: 978-0-494-51449-8

Our file Notre référence

ISBN: 978-0-494-51449-8

NOTICE:

The author has granted a nonexclusive license allowing Library and Archives Canada to reproduce, publish, archive, preserve, conserve, communicate to the public by telecommunication or on the Internet, loan, distribute and sell theses worldwide, for commercial or noncommercial purposes, in microform, paper, electronic and/or any other formats.

The author retains copyright ownership and moral rights in this thesis. Neither the thesis nor substantial extracts from it may be printed or otherwise reproduced without the author's permission.
AVIS:

L'auteur a accordé une licence non exclusive permettant à la Bibliothèque et Archives Canada de reproduire, publier, archiver, sauvegarder, conserver, transmettre au public par télécommunication ou par l'Internet, prêter, distribuer et vendre des thèses partout dans le monde, à des fins commerciales ou autres, sur support microforme, papier, électronique et/ou autres formats.

L'auteur conserve la propriété du droit d'auteur et des droits moraux qui protège cette thèse. $\mathrm{Ni}$ la thèse ni des extraits substantiels de celle-ci ne doivent être imprimés ou autrement reproduits sans son autorisation.
In compliance with the Canadian

Privacy Act some supporting forms may have been removed from this thesis.

While these forms may be included in the document page count, their removal does not represent any loss of content from the thesis.
Conformément à la loi canadienne sur la protection de la vie privée, quelques formulaires secondaires ont été enlevés de cette thèse.

Bien que ces formulaires aient inclus dans la pagination, il n'y aura aucun contenu manquant.

\section{Canada}




\begin{abstract}
This thesis discusses results on the development of three-dimensional (3D) Ni-based electrocatalytic layers for hydrogen production by water electrolysis in an acidic medium. This is of relevance to the development of polymer-electrolyte-membrane (PEM) hydrogen generators, which are promising hydrogen production systems suitable for both residential and industrial applications.
\end{abstract}

It was demonstrated that patterning of a glassy carbon electrode substrate with a 3D polyaniline (PANI) matrix is a convenient way of increasing the electrocatalytically active surface area of electrodeposited $\mathrm{Ni}$, and hence its apparent electrocatalytic activity. The optimized PANI/Ni electrocatalyst layer showed a significantly higher activity in the hydrogen evolution reaction (HER) then a commercially available Ni-plate surface (control surface).

It was also demonstrated that it is possible to produce a Ni-based HER electrocatalyst layer by synthesizing Ni nanoparticles and supporting them on Vulcan carbon. This electrocatalyst also offered a significantly higher electrocatalytic activity in the HER then the control surface, but lower then the optimized PANI/Ni electrocatalyst. 
The electrocatalytic activity of the optimized PANI/Ni layer was also compared to the activity of a 3D catalyst produced by electro-coating a porous reticulated vitreous carbon (RVC) substrate with Ni. This electrocatalyst showed the highest HER electrocatalytic activity among the investigated layers when tested under potentiodynamic polarization conditions. However, under the potentiostatic conditions, the optimized PANI/Ni layer showed the highest electrocatalytic activity.

The mechanisms and kinetics of the HER on the produced electrocatalysts was also investigated, as well as the electrocatalyst layers' surface morphology and crystalline structure. 


\section{RÉSUMÉ}

Cette thèse discute les résultats de la préparation de couches électrocatalytiques tridimensionnelles $(3 \mathrm{D})$ à base de $\mathrm{Ni}$, pour la production d'hydrogène par électrolyse de l'eau dans un milieu acide. Ceci est valeureux pour le développement des générateurs d'hydrogène de la polymère-électrolyte-membrane (PEM), qui promettent des systèmes de production d'hydrogène utiles dans les applications résidentielles et industrielles.

Modeler d'un substrat vitreux d'électrode de carbone avec une matrice de polyaniline 3D (PANI) a déjà été prouvé être une manière commode pour augmenter la surface active de $\mathrm{Ni}$ déposé, par suite son activité électrocatalytique apparente. La couche améliorée d'électrocatalyseur de PANI/Ni a établi une activité certainement plus élevée dans la réaction d'évolution d'hydrogène (HER) que dans une couche de Ni disponible dans le commerce (surface de contrôle).

La possibilité de produire des couches d'électrocatalyseur à base de $\mathrm{Ni}$ par synthèse de nanoparticules de $\mathrm{Ni}$ supportées par du carbone de Vulcan, a aussi été affirmée. Cet électrocatalyseur a également produit une activité électrocatalytique nettement plus élevée dans la HER que dans la surface de contrôle, mais moins élevée que dans la couche améliorée d'électrocatalyseur de PANI/Ni. 
L'activité électrocatalytique de la couche améliorée de PANI/Ni a aussi été comparée à l'activité d'un catalyseur 3D produit par enduction d'un substrat réticulé, vitreux et poreux en carbone (RVC) de Ni. Cet électrocatalyseur a manifesté l'activité électrocatalytique la plus élevée parmi les couches étudiées quand celle-ci a été observée dans des conditions potentio-dynamiques de polarisation. Cependant, dans des conditions potentio-statiques, la couche améliorée de PANI/Ni a révélé l'activité électrocatalytique la plus élevée.

Les mécanismes et la cinétique de la HER sur les électrocatalyseurs produits ont aussi été étudiés, ainsi que la morphologie extérieure de la couche de l'électrocatalyseur et la composition cristalline. 


\section{ACKNOWLEDGEMENTS}

I would like to express my most sincere gratitude to all the people who contributed through their support and encouragements to making the completion of this thesis possible. To Dr. Sasha Omanovic, my research supervisor, I express my deepest appreciation for his valuable guidance and support. His ideas, suggestions, and constant collaborations made possible the successful completion of this project.

My appreciation goes to the Natural Sciences and Engineering Research Council of Canada (NSERC) postgraduate scholarship and to the Eugenie Ulmer Lamothe scholarship for their financial support they provided me with to pursue a graduate degree.

Special thanks to the members of the electrochemical group: Tania Skaf, Marie-Josee Desroches, Khawtar Ahmed, Nadia Afara, Arash Shahryari, Saad Ghareba, Alexis Damian, Hooman Hennessey, and Jeffrey Harvey for all their help and good company.

I wish to thank to S. Kelly Sears and Jeannie Mui for helping me with the TEM. I also extend my gratefulness to Arash Shahryari for his help with the SEM images. I would like to thank all the technicians and support staff that helped during my research. Thanks to Samah Ghaoucha and Aram Chehayeb for their help in translating the abstract to French.

Finally, I would like to thank my family for all their love, support, and encouragement. 


\section{TABLE OF CONTENTS}

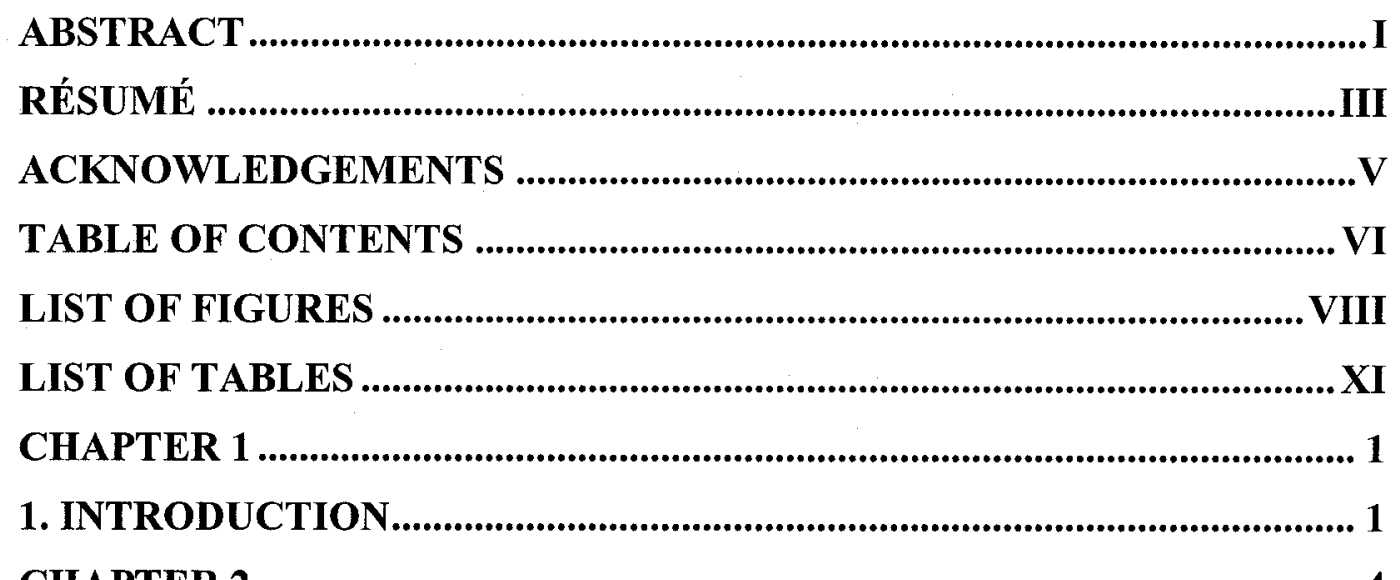

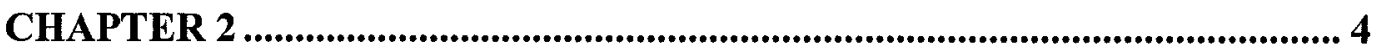

2. LITERATURE REVIEW .................................................................... 4

2.1 TECHNOLOGY OF WATER ELECTROLYSIS .............................................. 4

2.1.1 Alkaline water-electrolysis technology ....................................... 5

2.1.2 PEM hydrogen generators ............................................................... 7

2.2 HYDROGEN EVOLUTION REACTION (HER) ........................................ 12

2.3 HER ELECTROCATALYSIS............................................................ 15

2.4 ELECTROCHEMICALLY SYNTHESIZED PANI COATINGS ........................ 18

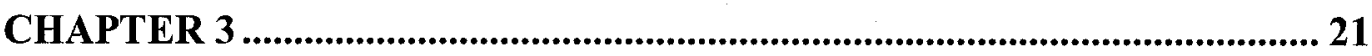

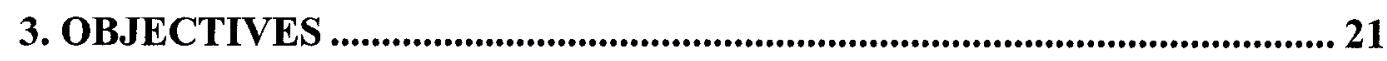

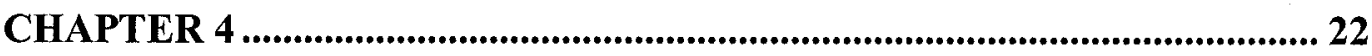

4. METHODOLOGY AND EXPERIMENTAL TECHNIQUES ................. 22

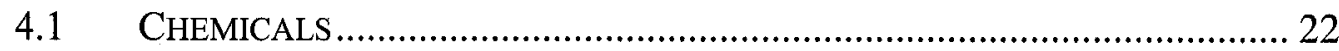

4.2 PRETREATMENT OF THE ELECTRODE SUBSTRATE ................................. 22

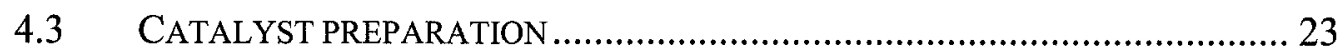

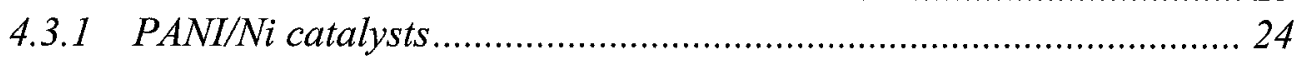

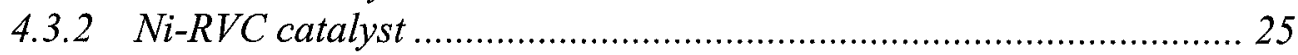

4.3.3 Carbon-supported Ni-nanoparticles............................................ 26

4.4 CATALYST PRETREATMENT ................................................................. 27

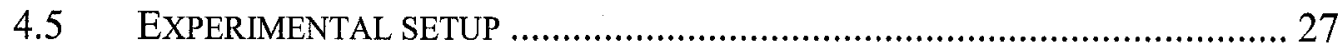

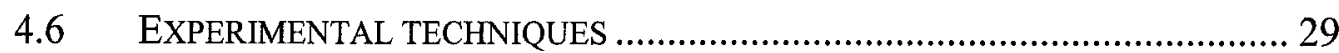

4.6.1 Linear Tafel DC polarization........................................................ 29

4.6.2 Electrochemical impedance spectroscopy (EIS)........................... 30

4.6.3 Characterization of the catalyst's morphology, particle size, and structural composition ........................................................................... 30

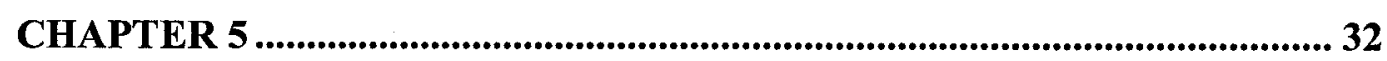

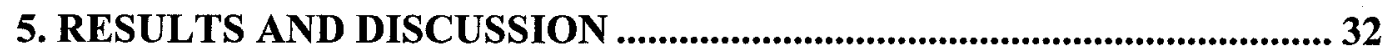

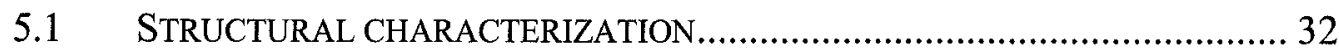


5.2 MORPHOLOGY OF ELECTRODES......................................................... 33

5.3 LINEAR DC POLARIZATION MEASUREMENTS.................................... 42

5.3 .1 PANI/Ni electrocatalyst layers ................................................. 42

5.3.2 Relative comparison of PANI/Ni, Ni-RVC and Ni-nanoparticle

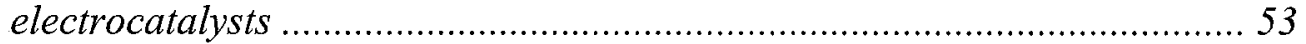

5.4 ELECTROCHEMICAL IMPEDANCE SPECTROSCOPY (EIS) MEASUREMENTS 57

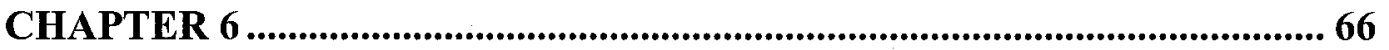

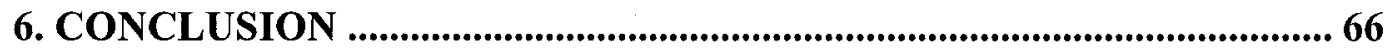

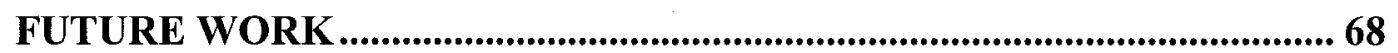

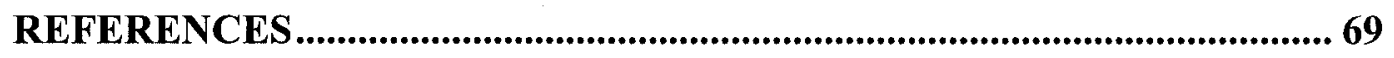

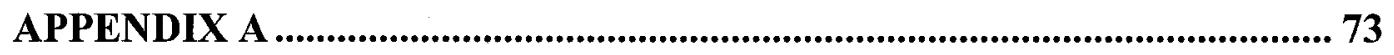




\section{LIST OF FIGURES}

Figure 2.1 Principle of operation of alkaline water electrolysis.

Figure 2.2 Schematic of PEM water electrolysis cell

Figure 2.3 Schematic representation of two PEM single cells connected in a series.

Figure 2.4 Exchange current (HER rate at reversible potential) for electrolytic hydrogen evolution vs. strength of intermediate metal-hydrogen bond formed during electrochemical reaction itself

Figure 2.5 Molecular structure of polyaniline (PANI) ............................... 19

Figure 2.6 Polymerization mechanism of PANI.

Figure 4.1 Picture of (a) bottom and (b) side view of GC electrode substrate.

Figure 4.2 Picture of RVC substrate. 26

Figure 4.3 Experimental setup for electrochemical measurements.

Figure 5.1 X-ray diffraction (XRD) patterns of Ni-based electrocatalysts. 32

Figure 5.2 SEM images showing the surface morphology of (a) the control surface and (b) polyaniline (PANI) electrodeposited on a GC substrate. . 34

Figure 5.3 SEM image of an electrocatalyst layer made by electrodeposition of Ni for 50 min at $-1.45 \mathrm{~V}$ on a pre-deposited PANI layer formed on a GC substrate during the period of $30 \mathrm{~min}$.

Figure 5.4 SEM images of an electrocatalyst layer made by electrodeposition of $\mathrm{Ni}$ for $50 \mathrm{~min}$ at (a) $-1.75 \mathrm{~V}$ and (b) $-1.85 \mathrm{~V}$ on a predeposited PANI layer formed on a GC substrate during the period of 30 $\min$.

Figure 5.5 SEM image showing the morphology of the Ni-RVC electrocatalyst.

Figure 5.6 TEM image showing Ni nanoparticles on a Vulcan carbon support synthesized at room temperature.

Figure 5.7 Linear polarization curves showing the influence of $\mathrm{Ni}$ deposition time. The curves were recorded on: (1) PANI30/Ni50, (2) 
PANI30/Ni40, (3) PANI30/Ni20 and (4) PANI30/Ni60. Scan rate $=0.5$ $\mathrm{mV} \mathrm{s}^{-1}$. The curves were corrected for the IR-drop. $\mathrm{Ni}$ was electrodeposited at $-1.45 \mathrm{~V}$. 43

Figure 5.8 Linear polarization curves showing the influence of PANI deposition time. The curves were recorded on: (1) PANI30/Ni20, (2) PANI40/Ni20, (3) PANI10/Ni20 and (4) PANI6/Ni20. Scan rate $=0.5 \mathrm{mV} \mathrm{s}^{-}$ 1. The curves were corrected for the IR-drop. Ni was deposited at $-1.45 \mathrm{~V}$.

Figure 5.9 Linear polarization curves showing the influence of $\mathrm{Ni}$ electrodeposition potential. The curves were recorded on PANI30/Ni50 formed by electrodeposition of $\mathrm{Ni}$ at (1) $-1.85 \mathrm{~V}$, (2) $-1.75 \mathrm{~V}$ and (3) -1.45 $V$. Scan rate $=0.5 \mathrm{mV} \mathrm{s}^{-1}$. The curves were corrected for the $I R$-drop...... 47

Figure 5.10 HER electrocatalytic activity of PANI/Ni electrocatalysts measured at $-0.35 \mathrm{~V}$. The bars show the influence of PANI electrodeposition time 48

Figure 5.11 HER electrocatalytic activity of PANI/Ni electrocatalysts measured at $-0.35 \mathrm{~V}$. The bars show the influence of $\mathrm{Ni}$ electrodeposition time.

Figure 5.12 HER electrocatalytic activity of PANI30/Ni50 electrocatalysts measured at $-0.35 \mathrm{~V}$. The bars show the influence of $\mathrm{Ni}$ electrodeposition potential. 51

Figure 5.13 Figure 6: HER electrocatalytic activity of PANI/Ni electrocatalysts measured at $-0.35 \mathrm{~V}$. The white bars show the influence of PANI electrodeposition time, while the grey bars show the influence of $\mathrm{Ni}$ electrodeposition time. In both cases $\mathrm{Ni}$ was electrodeposited at $-1.45 \mathrm{~V}$. The black bars show the influence of Ni electrodeposition potential. .........52

Figure 5.14 Linear polarization curves recorded on: (1) Ni-RVC, (2) PANI30/Ni50-1.85V, (3) Ni-nanoparticles and (4) the control Ni-plate surface. Scan rate $=0.5 \mathrm{mV} \mathrm{s}^{-1}$. The curves were corrected for the IRdrop. 54

Figure 5.15 Nyquist plot showing the EIS response of PANI30/Ni50-1.85V electrocatalyst at various overpotentials in the HER region. Symbols are experimental and solid lines are modeled data. (O) $-0.37 \mathrm{~V},(\Delta)-0.42 \mathrm{~V}$, $(\diamond)-0.47 \mathrm{~V}$, and $(\square)-0.52 \mathrm{~V}$ 58

Figure 5.16 EEC models used to fit the EIS response of the investigated electrocatalysts in the HER: (a) one-time constant, and (b) two-time constant serial model. $\mathrm{R}=$ resistance, $\mathrm{CPE}=$ constant phase element. . 59 
Figure 5.17 Nyquist plots showing the EIS response of (a) Ni-RVC, and (b) Ni-nanoparticle electrocatalysts at various overpotentials in the HER region. Symbols are experimental and solid lines are modeled data. (O) $0.35 \mathrm{~V},(\Delta)-0.40 \mathrm{~V}$, and $(\diamond)-0.48 \mathrm{~V}$

Figure 5.18 Relative electrocatalytic activity of the investigated electrocatalysts in the HER. The data were calculated from charge transfer resistance values obtained from EIS measurements performed in the potential region relevant to the operation of a hydrogen generator $(-0.35 \mathrm{~V}$ to $-0.40 \mathrm{~V})$.

Figure A.1 Nyquist plot showing the EIS response of control Ni-plate surface at various overpotentials in the HER region. Symbols are experimental and solid lines are modeled data. (O) $-0.37 \mathrm{~V},(\Delta)-0.42 \mathrm{~V}$, $(\diamond)-0.47 \mathrm{~V}$, and $(\square)-0.52 \mathrm{~V}$. 


\section{LIST OF TABLES}

Table 4.1 Experimental conditions used in preparation of PANI/Ni electrocatalysts on a GC substrate.

Table 4.2 Experimental conditions used in preparation of $\mathrm{Ni}$ catalyst on RVC substrate.

Table 5.1 HER kinetic parameters obtained by analysis of the curves presented in Fig. 5.14.

Table A.1 EEC parameters obtained by fitting EIS experimental spectra recorded at various overpotentials on the control $\mathrm{Ni}$ plate and PANI30/Ni50 -1.85 V electrocatalyst. 73

Table A.2 EEC parameters obtained by fitting EIS experimental spectra recorded at various overpotentials on the Ni-RVC and Ni-nanoparticle electrocatalysts. 


\section{CHAPTER 1}

\section{INTRODUCTION}

The renewed interest in hydrogen is explained by several converging forces. The advent of greater competition in the energy industry and the technological advances are part of the equation. However, equally important motivations for investigating the different uses of hydrogen are the problems of the current energy systems, which are derived primarily from fossil fuels. A range of socio-economical, geopolitical, and environmental problems are expected to increase as the availability of oil and other fossil fuels is continuing to decrease. At the same time the utilization of fossil fuels, especially oil, is exponentially increasing. We have just recently witnessed a large increase in crude oil price, from $\$ 80$ in September 2007 to over $\$ 100$ in early January 2008. Such problems collectively call for the need to utilize sustainable sources of energy [1-4].

One of the most promising energy carriers of the future is hydrogen, the simplest and most abundant element on earth. It is a high efficiency, environmentally friendly fuel (vector) that can be produced, handled and utilized safely. Hydrogen has many potential energy uses, such as in residential power-supply units, a variety of industrial uses, electric utilities, and zero-pollution vehicles (which includes both the internal-combustionengine and fuel-cell powered vehicles). Therefore, hydrogen is increasingly considered as the "fuel of the future" [1-4]. 
According to the U.S. Department of Energy (DOE), steam methane reforming, currently the most common and least expensive way to produce hydrogen, provides roughly $48 \%$ of the world's hydrogen. Nevertheless, this process also produces $\mathrm{CO}$, a health hazard and the major poison for hydrogen fuel-cell catalysts, especially those used in various industrial processes occurring at temperatures below $150{ }^{\circ} \mathrm{C}$. It also produces $\mathrm{CO}_{2}$ (the primary green-house gas). Although it is not currently cost competitive to natural gas reformation, hydrogen production by water electrolysis is the most promising technique to produce hydrogen. It represents the only process where hydrogen can be produced by true renewable and fully environmentally friendly energy sources, without the evolution of the green-house gas, $\mathrm{CO}_{2}$.

Only a small percentage of the world's hydrogen (only $4 \%$, reported by the U.S. DOE) is currently produced by water electrolysis, most of which is supplied to applications requiring small volumes of high purity hydrogen. Nevertheless, due to the increasing interest in using hydrogen as a fossil fuel replacement, it is expected that the need to produce pure hydrogen by water electrolysis is going to significantly increase. However, one of the major obstacles associated with the wider use of water electrolysers (i.e. hydrogen generators) is related to high investment costs, a large portion of which goes to electrocatalysts. Therefore, it is important to develop more active, efficient, stable, and cheap electro catalysts for water splitting in the hydrogen generators that would offer low overpotentials for hydrogen evolution reaction (HER) at rather high current 
densities (high production rates), and therefore lower the overall cost of hydrogen.

The aim of this research project is to develop new active, efficient, stable, and low cost nickel-based electrocatalysts for hydrogen production by water electrolysis. This thesis also represents the first report on the use of carbon-supported nickel-nanoparticles as catalyst for hydrogen production.

The thesis is divided into six chapters, Chapters 1 and 2 present an introduction to the subject and the theoretical background, respectively. In these sections the polymer-electrolyte-membrane (PEM) technology is described as well as the characteristics of the hydrogen evolution reaction (HER) and the electrocatalyst development. Chapter 3 states the objectives of this study. Chapter 4 describes the experimental procedures and techniques employed in the research. Chapter 5 presents and discusses all the experimental results. Finally, Chapter 6 contains the conclusions and suggestions for future work. 


\section{CHAPTER 2}

\section{LITERATURE REVIEW}

\subsection{Technology of water electrolysis}

The history of water electrolysis dates back to as early as the first industrial revolution, when, in the year 1800, Nicholson and Charlise accidentally discovered the ability to split water [5]. Few years after publishing their work, electrolysis had been used by Humphry Davy to isolate sodium, potassium, calcium, strontium, barium, magnesium, and lithium. By 1902 more than 400 industrial water electrolyzers were in operation, and in 1939 the first large-scale water electrolysis plant with a capacity of $10000 \mathrm{~m}^{3} \mathrm{H}_{2} \mathrm{~h}^{-1}$ went into operation, and in 1949 the first pressurized industrial electrolyzer by Zdansky/Lonza was built [6]. Currently, the development of a new water-electrolysis technology based on the use of polymer-electrolyte membranes (i.e. PEM-type generators), and the optimization and reconstruction of the old (classical) alkaline water electrolyzers that have been in use for long time, is the subject of intensive research in old developed countries. 


\subsubsection{Alkaline water-electrolysis technology}

Although the discovery of the water electrolysis process was made in acidic medium, industrial plants still prefer using an alkaline medium. This is because corrosion is more easily controlled and cheaper construction materials can be used than in acidic electrolysis technology [6].

Aqueous potassium hydroxide $(\mathrm{KOH})$ has traditionally been used as an electrolyte in alkaline water electrolyzers, due to its high ionic conductivity; a $20-30$ wt\% solution has been used because of the optimal (maximum) ionic conductivity and remarkable corrosion resistance of stainless steel in this concentration range. Typical operating temperatures and pressures of such electrolyzers are $70-100{ }^{\circ} \mathrm{C}$ and 1-30 bars, respectively [7].

The principle of operation of alkaline water electrolysis is shown schematically in Fig. 2.1. 


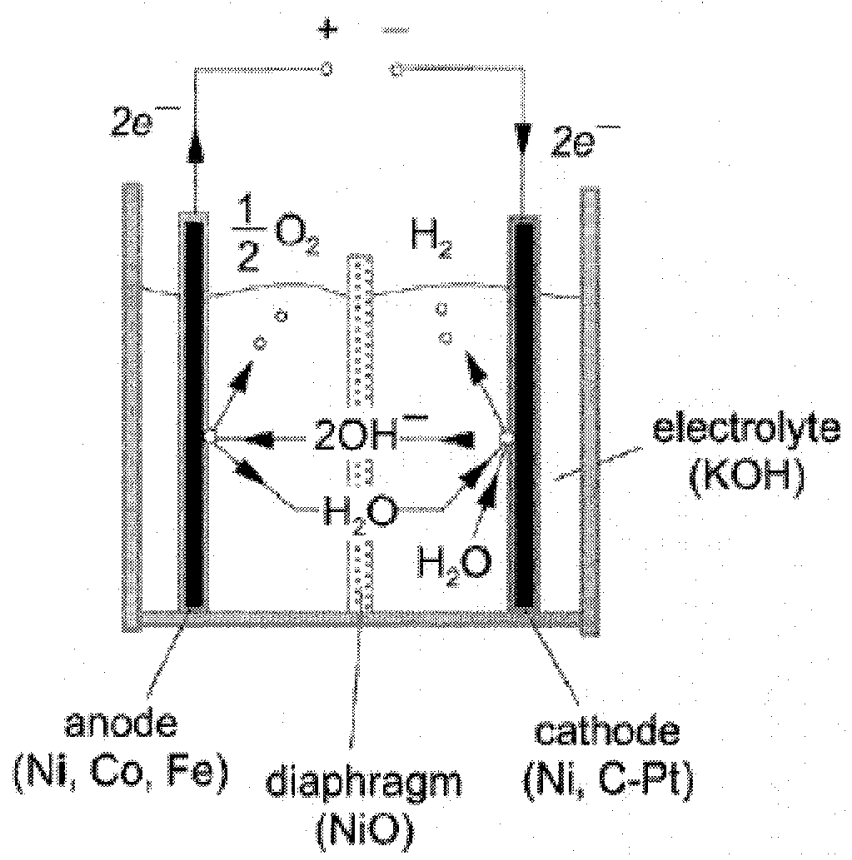

Figure 2.1 Principle of operation of alkaline water electrolysis [7].

The following reactions occur at each electrode in an alkaline system [7]:

Cathode: $2 \mathrm{H}_{2} \mathrm{O}+2 \mathrm{e}^{-} \rightarrow \mathrm{H}_{2}+2 \mathrm{OH}^{-}$

Anode: $2 \mathrm{OH}^{-} \rightarrow 1 / 2 \mathrm{O}_{2}+\mathrm{H}_{2} \mathrm{O}+2 \mathrm{e}^{-}$

The major disadvantages of the alkaline process are high energy consumption, low specific production, low efficiency (up to $65 \%$ ), voluminous systems, and safety issues related to the use of caustic electrolytes [8]. Voluminous systems and safety issues make this technology not suitable for most residential and small scale applications. Improvements to the design of alkaline electrolyzers include: (1) the use of new cell configurations to reduce the surface-specific cell resistance at high current densities, (2) higher process temperatures to reduce the electric cell resistance in order to increase the electric conductivity of the electrolyte and improve the kinetics of hydrogen and oxygen evolution, 
and (3) the use of new electrocatalysts to reduce anodic and cathodic overpotentials [7].

\subsubsection{PEM hydrogen generators}

Polymer electrolyte membrane (PEM) hydrogen generators would offer a viable alternative to the alkaline process, especially for residential, small scale and special (space, military, etc.) applications. The advantages of this technology are described in detail in Chapter 2.1.2.3. The PEM technology was invented by General Electric in 1966 for space applications [9], and since then it has been the subject of intensive research in the area of fuel-cells development. Extensive research and development on PEM electrolysers has been performed within the Japanese WE-NET program $[4,10,11]$. The Swiss firm ABB developed its MEMBREL process both for water electrolysis and ozone generation in the period between 1976 - 1989 [12]. This technology basically consists of coating or hot pressing two electrocatalyst layers on to each side of a PEM membrane (Fig. 2.2), which is used as an electrolyte. The PEM hydrogen generator technology is very similar to the PEM technology used in the hydrogen and direct-methanol fuel cells, which have already been commercialized, and will be explained in Chapter 2.1.2.2. 


\subsubsection{PEM membrane materials}

To function as an electrolyte in the PEM hydrogen generator, the membrane must conduct hydrogen ions (protons) but not electrons as this would "short circuit" the cell (i.e. the two electrodes). The membrane must also not allow either gas (hydrogen and oxygen) to pass to the opposite side of the cell, a problem known as "gas crossover". Finally, the membrane must be resistant to the reducing environment at the cathode as well as the harsh oxidative environment at the anode. Present day PEM materials are based on perfluorosulphonic acid polymers. These materials are long chain polymers, consisting of $\mathrm{CF}_{2}$ backbones with $\mathrm{SO}_{3}$-terminated $\mathrm{CF}_{2}$ side groups [13]. Charge carriers in the membrane are hydrated hydrogen ions which move through the solid electrolyte (membrane) by passing from one sulphonic acid group to the next neighboring one (hydrogen hopping mechanism). Providing sufficient hydration of the membrane, this mechanism makes the membrane highly ionically conductive. The acid groups in the membrane create a highly acidic environment (equal to that of $20 \mathrm{wt} \%$ sulfuric acid). Therefore, acid resistant metals must be used as electrocatalysts and to build other parts that are in contact with the PEM (bi-polar plates, end-plates, current collectors) [14].

Nafion ${ }^{\circledR}$ products of Du Pont have most commonly been used as PEMs in hydrogen and direct-methanol fuel cells, because of their intrinsic properties (excellent mechanical and chemical stability, high ionic 
conductivity and gas impermeability). Although little progress has been made to develop alternatives, Dow Chemical has also developed membranes with very similar characteristics [15]. The same PEMs could also be used in PEM hydrogen generators.

\subsubsection{PEM hydrogen generator configuration}

A schematic of a PEM water electrolyzer (hydrogen generator) is shown in Fig. 2.2.

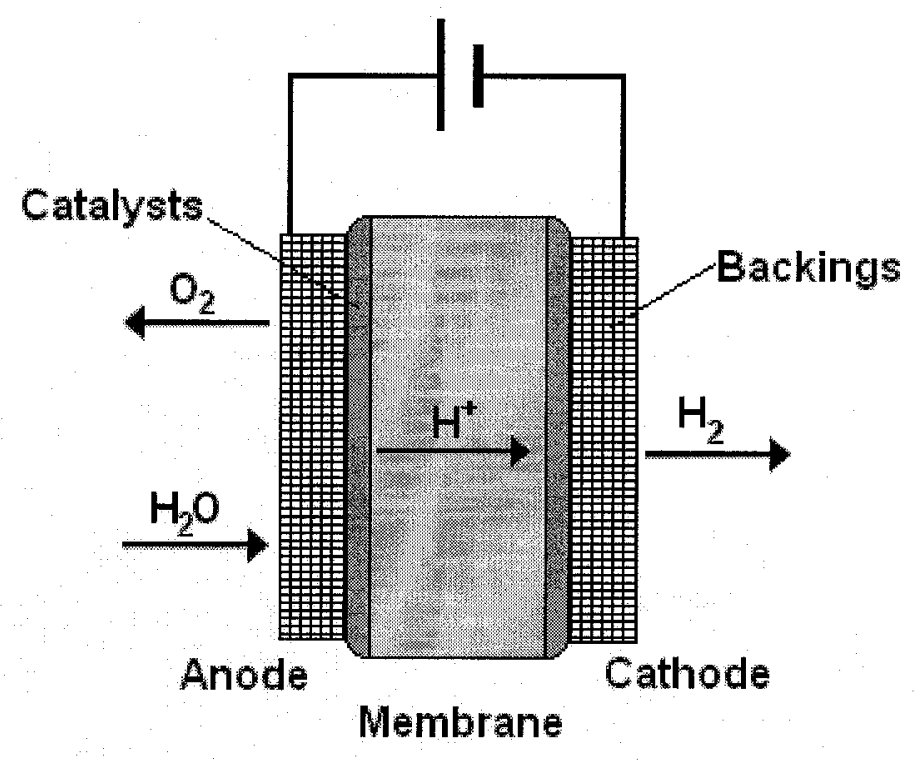

Figure 2.2 Schematic of PEM water electrolysis cell [16]

The PEM water electrolysis single cell consists of a polymer electrolyte membrane (PEM) on which the anode (usually Ir or $\mathrm{IrO}_{2}$ ) and the cathode (usually Pt) are coated or hot-pressed. Such configuration is called a membrane electrode assembly (MEA), which is also used in the fuel cell 
technology. The electrical contact and mechanical support is established with porous backings like metallic meshes or sinters. In order to increase the hydrogen production capacity, a number of single cells can be arranged in a series, to give a PEM stack (Fig. 2.3). A chemically and mechanically stable electrically conductive material used as a separator between the anode chamber of one cell and the cathode chamber of the adjacent cell, also serves as a current collector (so-called 'bi-polar plate). Hydrogen is produced in the cell by supplying water to the anode where it decomposes electrochemically producing $\mathrm{O}_{2}$ gas, hydrogen ions and electrons (Eq. 2.4). The hydrogen ions move through the PEM membrane and recombine electrochemically with electrons at the surface of the cathode catalyst to form hydrogen gas in the cathode chamber (Eq. 2.3).

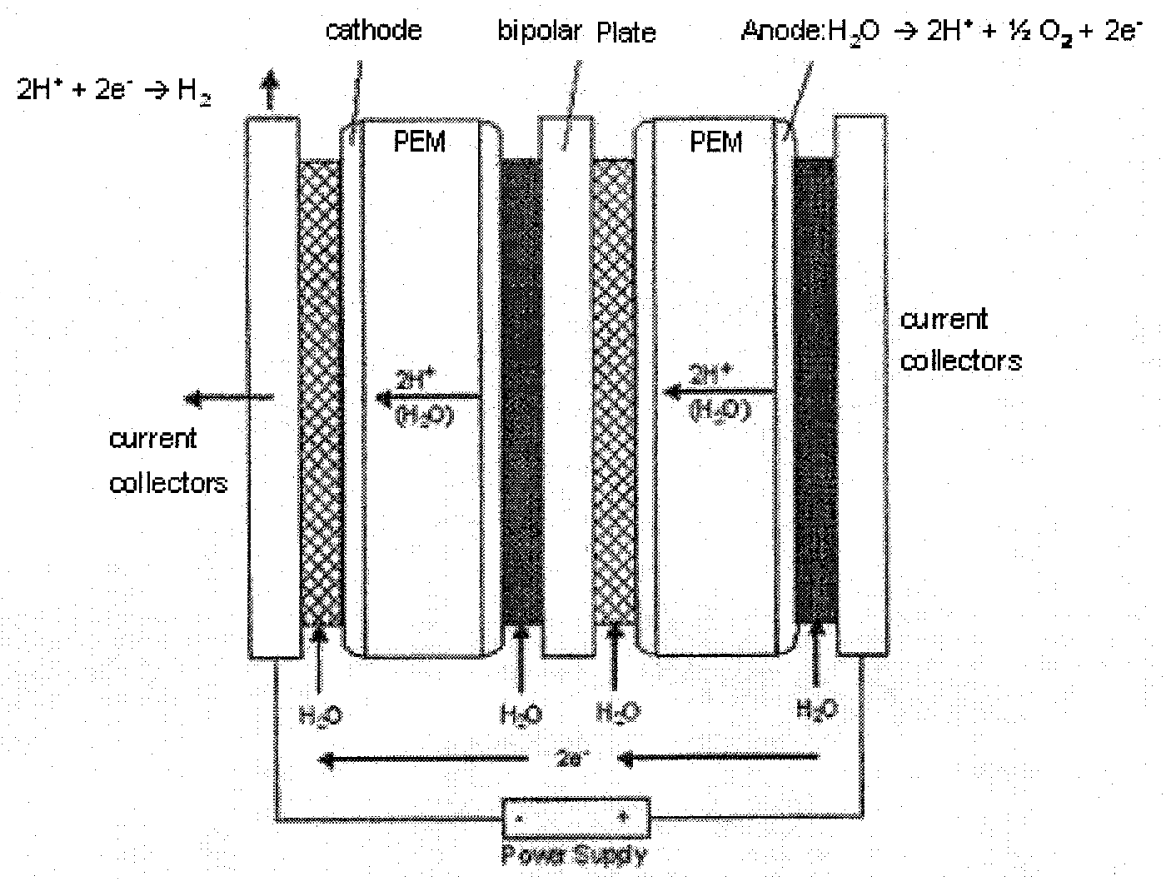

Figure 2.3 Schematic representation of two PEM single cells connected in a series [17]. 
The following are the reactions that take place at each electrode in a PEM system [17]:

$$
\begin{aligned}
& \text { Cathode: } 2 \mathrm{H}^{+}+2 \mathrm{e}^{-} \rightarrow \mathrm{H}_{2} \\
& \text { Anode: } \mathrm{H}_{2} \mathrm{O} \rightarrow 1 / 2 \mathrm{O}_{2}+2 \mathrm{H}^{+}+2 \mathrm{e}^{-}
\end{aligned}
$$

The ideal MEA must have the following properties in order to achieve highly efficient electrolysis: (1) the catalyst film should be deposited predominantly within the Nafion thin layer adjacent to the membrane surface, (2) a large electrode/membrane contact area to provide an electrochemically large active surface area, (3) good inter particle contact for low electronic resistance, and (4) porous structure for free mass transfer of water and gases, a large 3D reaction zone that enhances a two-interface contact [17].

\subsubsection{Advantages and disadvantages of PEM hydrogen generators}

Proton exchange membrane (PEM) water electrolysis systems based on the fuel-cell technology to produce hydrogen from demineralized water offer several advantages over traditional alkaline technologies. This technology offers greater safety and reliability since no caustic electrolyte is circulated in the cell stack. It offers greater energy efficiency and production rates, a more compact design, higher gas purity, and offers construction simplicity and lower maintenance costs $[8,16]$. In addition, some membrane materials are efficient in preventing gas mixing and can sustain higher differential pressures without being damaged [18]. 
Moreover, the nature of the PEM electrolyte permits a quick start-up and a rapid shut-down since the electrolyte need not be circulated until the reagents are removed to prevent explosive mixing [13].

The advantages mentioned above make this technology a promising one especially for residential, small scale and special (military, space, etc.) applications. However, one of the major obstacles associated with the wider use of PEM water electrolysers (i.e. hydrogen generators) is related to high investment costs, a large portion of which goes to electrocatalysts (electrodes) [8]. Many research groups have been involved in the development of PEM-hydrogen generators, but all of them have used only noble metals as electrocatalysts. Therefore there is a great need for development of new active, efficient, stable, and cheap electrocatalysts for water splitting in the PEM-hydrogen generator, which would offer low overpotentials for the hydrogen evolution reaction at high current densities (1-2 $\left.\mathrm{A} \mathrm{cm}^{-2}\right)$ [4]. It is also important to build better MEAs, which would be based on the nano-technology utilized for constructing low-temperature fuel-cell MEAs.

\subsection{Hydrogen evolution reaction (HER)}

Understanding the principles of the HER mechanisms and kinetics is crucial for the development of new electrocatalysts. This reaction is also of great importance in fundamental and technological electrochemistry and has been widely studied using a broad range of solution conditions and electrode materials $[19,20]$. During water electrolysis, the HER on a 
metallic electrode $(M)$, in acidic media, proceeds according to the following three-reaction-step mechanism [21].

$$
\begin{array}{ll}
M+H^{+}+e^{-} \leftrightarrow M-H_{a d s} & \text { (Volmer reaction) } \\
M-H_{\text {ads }}+H^{+}+e^{-} \leftarrow \rightarrow H_{2}+M & \text { (Heyrovsky reaction) } \\
M-H_{\text {ads }}+M-H_{\text {ads }} \leftrightarrow \rightarrow H_{2}+2 M & \text { (Tafel reaction) }
\end{array}
$$

The first reaction (Volmer reaction) is electroreduction of the proton with the formation of hydrogen adsorbed on the electrode surface, $\mathrm{M}-\mathrm{H}_{\mathrm{ads}}$. This is followed either by the electrochemical (Heyrovsky reaction) or chemical (Tafel reaction) desorption of hydrogen. The adsorbed hydrogen atom $\left(\mathrm{M}-\mathrm{H}_{\mathrm{ads}}\right)$ plays a significant role in the HER mechanisms and kinetics, governing both its thermodynamics and kinetics. Both mechanisms, Volmer-Heyrovsky and Volmer-Tafel, require the formation and then cleavage of the $\mathrm{M}-\mathrm{H}_{\mathrm{ads}}$ bond. Hence, the reaction rate for the HER is determined by the strength of the hydrogen-metal adsorption bond. Consequently the maximum rate of hydrogen evolution will occur at intermediate values of $\mathrm{M}-\mathrm{H}_{\text {ads }}$ bond strength, resulting in a behavior characterized by the "volcano curve", shown in Fig. 2.4 [22]. 


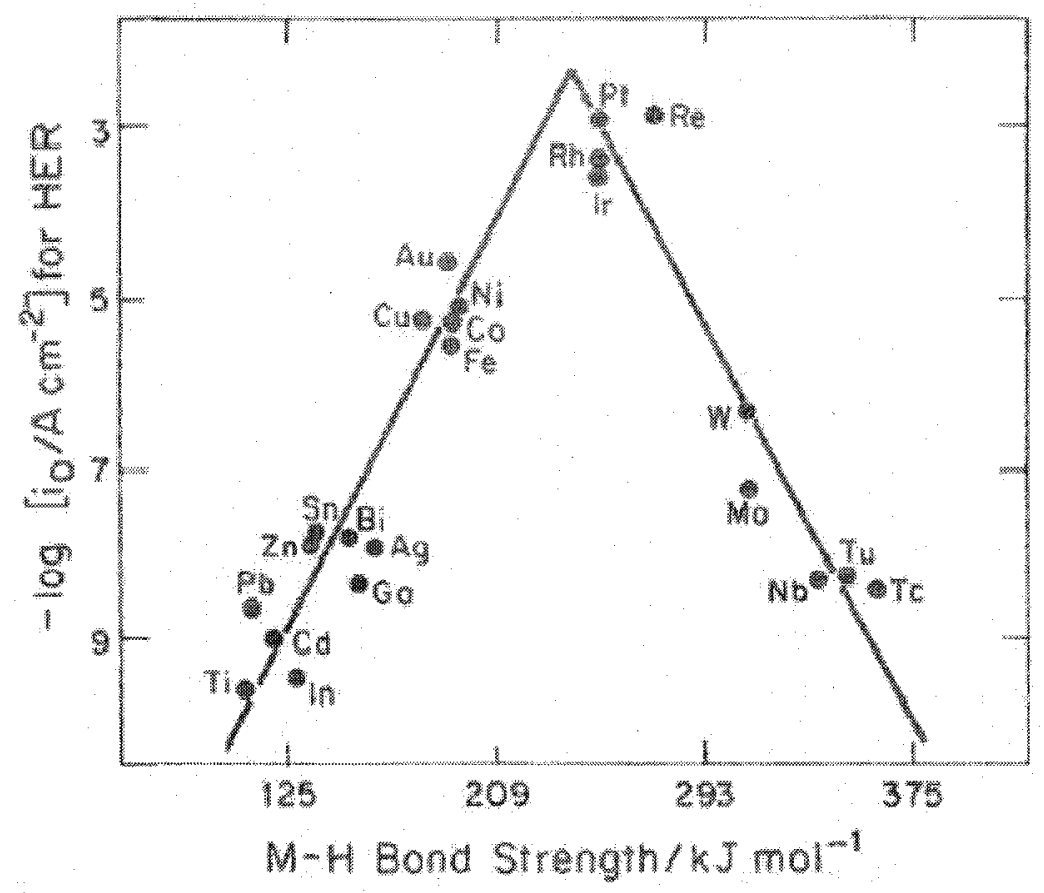

Figure 2.4 Exchange current (HER rate at reversible potential) for electrolytic hydrogen evolution vs. strength of intermediate metal-hydrogen bond formed during electrochemical reaction itself [22].

Unfortunately, it is clear from the figure that only noble metals (e.g. Pt, Rh, Re, Pd, Ir) express high HER activity, while less noble pure metals express much lower activity [22]. This is due to the fact that Pt- and Ir-group of metals have almost filled d-orbital, thus making the $\mathrm{M}-\mathrm{H}_{\text {ads }}$ bond of an intermediate strength. Therefore the basis for the design of a cheap non-noble HER catalyst is designing a material that would express d-electronic density similar to Pt-group metals and in that way at least approach the electrochemical activity in the HER similar to the noble metals. A previous study in our laboratory [23] has shown that combining nickel with some transition metals results in the change of the electron 
density of states in the outer $d$-shell, thus changing the strength of the $\mathrm{M}-\mathrm{H}_{\mathrm{ads}}$ bond.

\subsection{HER Electrocatalysis}

Three characteristics play a crucial role in selecting catalytically active materials for the HER: (1) an actual intrinsic electrocatalytic effect of the material, (2) a large active surface area per unit volume ratio, and (3) catalyst stability [8].

The main focus of research in the area of HER catalyst development has been on several important parameters such as the intrinsic nature of the reaction [19, 24-26], electrode composition [27-31], surface morphology $[19,25,26,30,32-36]$, structural, chemical and electronic properties [27-29, 31, 37, 38], and physical, chemical and electrochemical activation treatments $[19,20,25,26,39,40]$.

In water electrolysis for hydrogen production, the cathode is required to have low hydrogen overpotential in order to minimize energy consumption [32]. Decreasing the overpotential can be accomplished by using a highly catalytically active electrode material for the HER and/or by increasing the active surface area of the electrode. Many efforts have been made to explain the characteristics of hydrogen overpotential of individual metals using various physical and electronic parameters such as the atomic number [41], the work function [42], the bond strength of metals [43], the heat of adsorption of hydrogen on metals [22], and the electro negativity [44]. It has been concluded from many studies that the intrinsic 
catalytic activity for the HER can be related to the electronic structure of metals. As mentioned earlier, alloying nickel with left transition metals, an increase in the intrinsic electrocatalytic activity in the HER, compared to pure nickel, can be obtained. However, the theoretical approach to explain the HER activity of alloy catalysts is even more complex than that of pure metals, and several theories have been proposed.

Enhancement of the electrocatalytic activity by increasing the active surface area has also been studied. Ni-based Raney-type alloys have been successfully used to fabricate HER cathodes in classical types of alkaline electrolyzers $[25,26,36,40,45]$. Nevertheless the very limited contact area between the solid electrolyte membrane and the active catalyst layer makes such types of electrodes unsuitable for the PEM-type hydrogen generator. Direct plating of platinum onto the polymer membrane is the best method to prepare the catalyst $[18,46]$. This is also known as the fabrication of the membrane electrode assembly (MEA), as mentioned earlier. The main drawback of the currently used MEA preparation method is the relatively low catalyst efficiency-to-loading ratio. This is mainly due to the limited polymer electrolyte/catalyst interface area and a rather high loading of the catalyst required to maintain the electrical contact. A possible solution would be to construct the MEA similar to the construction used in the PEM fuel cell [47]. This would allow for lower catalyst loading to be used. However, the issue of designing a cheaper material to be used as a catalyst in the PEM-type hydrogen generator has also attracted a great interest, due to the high cost associated with using 
noble metals such as Pt, Ru, and Ir. If we inspect Fig. 2.4., we will see that the element that offers the closest electrocatalytic activity in the HER to that of noble metals is $\mathrm{Ni}$. At the same time, this metal is considerably cheaper then the noble metals ( $1 \mathrm{~kg}$ of $\mathrm{Ni}$ costs $\$ 27$ and $1 \mathrm{~kg}$ of Pt costs $\$ 56000$ [48]. Therefore, hydrogen evolution on porous Ni-based electrodes in an alkaline medium have been studied during the past few years $[25,26,36,40,45,49]$. There are various types of high surface area nickel electrodes and a large variety of preparation methods [50]. For example, Brown et al. [50] have shown that nickel can be electroplated thorough the pores of a generic microporous polymer coating onto the cathode and subsequent thermal decomposition results in a porous $\mathrm{Ni}$ coating. These cathodes showed promising current densities for hydrogen evolution. As already mentioned previously, Ni-based Raney-type alloys have been successfully used to fabricate large-surface-area HER cathodes in classical types of alkaline electrolyzers [25, 26, 36, 40, 45]. These electrodes are produced by alloying $\mathrm{Ni}$ and some other metal (e.g. $\mathrm{Zn}$ or $\mathrm{Al}$ ), and then leacing out $\mathrm{Zn}$ or $\mathrm{Al}$ using $\mathrm{NaOH}$, which leaves a highly-porous $\mathrm{Ni}$ structure. However, these electrodes are not suitable for the PEM-type hydrogen generator. On the other hand, The work done in our laboratory by Navarro-Flores et al. [8] has shown that incorporating a small amount of nickel into a thick pre-deposited polyaniline (PANI) layer greatly enhanced the electroctalytic activity of the catalyst layer, due to an incrase in the catalyst's area available for the HER. However, the authors 
have not optimized this promising method, which is one of the goals of this thesis.

\subsection{Electrochemically synthesized PANI coatings}

Conductive polymers (CPs) have attracted attention of many researchers because of their unique properties and versatility. Their conjugated $\pi$ system is the major and most important property of CPs. It allows them to extend beyond the monomer and allow electron delocalization along the polymer chain which in turn gives a conductive character to the material [51]. By chemical modification, the conductivity of CPs can be tuned from insulating to superconducting. Chemical and electrochemical methods can be used to prepare conjugated polymers. Chemical synthesis is performed by oxidation or reduction of the monomer, in a liquid or gas phase, sometimes by thermal autopolymerization [51]. The polymers produced by chemical synthesis are expected to have ordered structures [52]. Electrochemical synthesis of these polymers is carried out by anodic oxidation of the monomers in suitable electrolytes either at constant potential or current, or even by cycling between different potentials [52]. Electrochemical methods have advantages over chemical methods because they offer control on the polymerization and doping level. They could also be applied directly on a substrate in order to fabricate devices directly [52].

The research presented in this thesis has focused on using polyaniline (PANI) as a Ni catalyst substrate to produce 3D Ni layers for 
their possible use in PEM hydrogen generators. This polymer has been chosen due to its (1) insulating properties in the cathodic region relevant for the hydrogen production, thus avoiding their catalytic interference with the HER charge transfer process and Ni catalysts, (2) favorable pattering morphology, (3) stability in the PEM environment of a hydrogen generator (low pH), (4) high solubility in aqueous solutions, (5) well-developed and simple electrochemical polymerization methodology, and (6) suitability for a potential commercial use [8]. The molecular structure of PANI and its polymerization mechanism is shown in Fig. 2.5 and Fig. 2.6, respectively. The project will build also on the results obtained previously in our laboratory by Navarro-Flores et al. [8] and investigate the influence of PANI and Ni deposition time on the resulting activity of the catalytic layer in the HER.<smiles>CC(C)(C)Nc1ccc(Nc2ccc(Nc3ccc(Nc4ccc(C(C)(C)C)cc4)cc3)cc2)cc1</smiles>

Figure 2.5 Molecular structure of polyaniline (PANI). 


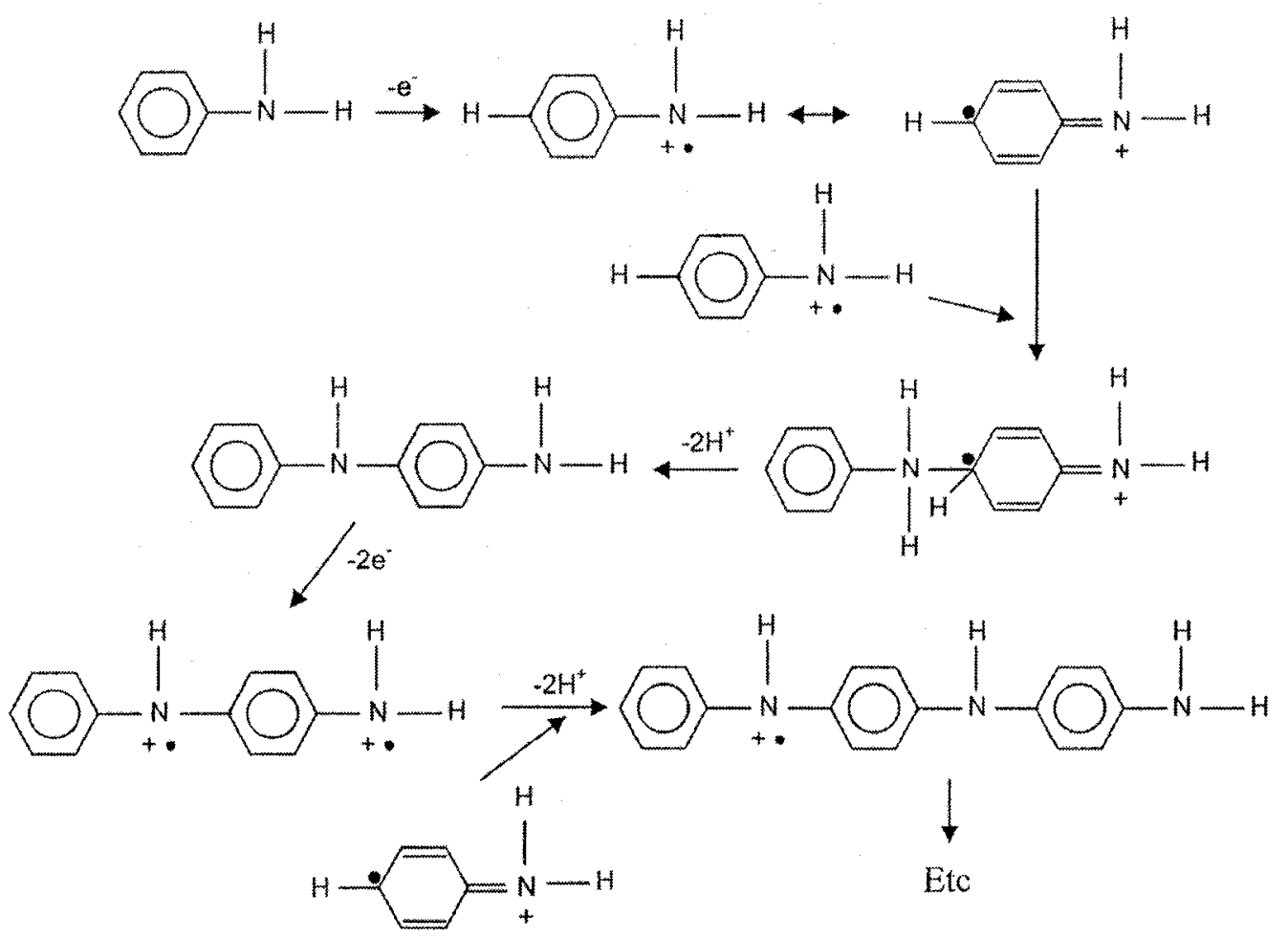

Figure 2.6 Polymerization mechanism of PANI. 


\section{CHAPTER 3}

\section{ObJectives}

The present work focuses on the development of Ni-based catalyst layers for the HER, with the aim to increase their active surface area and activity by:

- Using conductive polymers (PANI) as catalyst pattering matrices for the development of Ni HER catalyst,

- Using chemically synthesized Ni-nanoparticles supported on cabon, and

- Using reticulated vitreous carbon (RVC) as a substrate for the electrodeposition of $\mathrm{Ni}$.

The additional objectives are:

- To investigate the catalysts' structural composition, and electrocatalytic activity in the HER using various experimental techniques, and

- To correlate the catalysts' activity in the HER to morphological properties of the catalyst layer. 


\section{CHAPTER 4}

\section{Methodology and eXPERIMental teChniQues}

\subsection{Chemicals}

Chemicals used in research were purchased from Sigma-Aldrich Company and Fisher Scientifics, and were used without further purification. Carbon black was purchased from Cabot Corp. and was purified by filtration in ethanol before use. All solutions were prepared using deionized water with a resistivity of $18 \mathrm{M} \Omega \mathrm{cm}$. All measurements were made in an oxygen-free solution, which was achieved by continuous purging of the cell electrolyte with argon gas purchased from MEGS (99.998\% pure).

\subsection{Pretreatment of the electrode substrate}

Electrodes used as substrates electrocatalyst coatings went through careful pretreatment before the electrocatalyst was deposited. Two types of substrates were used for nickel electrodeposition, glassy carbon (GC) (Fig. 4.1) and reticulated vitreous carbon (RVC) (Fig. 4.2). GC was chosen as a substrate material since it has very large overpotential for hydrogen evolution, thus offering a wide potential region for the investigation of the HER, without the substrate interference. RVC was chosen as a substrate due to its high area/volume ratio, high porosity, good electrical 
conductivity, high liquid permeability and its chemical and electrochemical inertness over a wide range of potential and chemicals.

In all experiments, the GC substrate was carefully prepared by mechanical wet-polishing using \#600 and \#1500 grit sand paper, followed by thorough rinsing with distilled water and cleaning in an ultrasonic bath for 5-6 $\mathrm{min}$ in order to remove polishing residues. The substrate was then degreased with ethanol, rinsed with deionized water, and further electrochemically cleaned (activated) in $0.5 \mathrm{M} \mathrm{H}_{2} \mathrm{SO}_{4}$ by potentiodynamic cycling between the hydrogen and oxygen evolution potential (between -1.1 and $+1.4 \mathrm{~V}$ vs. a saturated calomel electrode) at a scan rate of $0.5 \mathrm{Vs}^{-1}$. The RVC substrate was rinsed with deionized water and activated in $0.5 \mathrm{M} \mathrm{H}_{2} \mathrm{SO}_{4}$ by potentiodynamic cycling between the hydrogen and oxygen evolution potential prior to the electrodeposition of nickel.

\subsection{Catalyst preparation}

The RVC substrate used for nickel electrodeposition was a cube of $1 \mathrm{~cm}^{3}$. The GC electrode (substrate) was made of a rectangular piece of GC sealed in an epoxy, thus giving a two-dimensional surface area $\left(0.27 \mathrm{~cm}^{2}\right)$ available for the deposition of the electrocatalytic layer. The GC substrate was used for the development of polyaniline/ $\mathrm{Ni}(\mathrm{PANI} / \mathrm{Ni}$ ) electrocatalysts and the electrochemical characterization of the chemically synthesized nickel-nanoparticles. 


\subsubsection{PANI/Ni catalysts}

The formation of PANI/Ni catalysts was done by potentiostatic electrodeposition of $\mathrm{Ni}$ on GC through a PANi layer pre-deposited on the GC substrate. The PANI layer was pre-formed by the electropolymerization from the corresponding monomer solution. Electropolymerization was carried out at constant potential. The specific experimental conditions and baths compositions are outlined in Table 4.1. The effect of $\mathrm{Ni}$ and PANI deposition time on the catalyst's activity in the HER was studied. In the text, PANIx/Niy-E catalysts are denoted in the way that " $\mathrm{x}$ " and " $\mathrm{y}$ " refer to the PANI and $\mathrm{Ni}$ electrodeposition times, respectively, and "E" to the Ni electrodeposition potential.

Table 4.1 Experimental conditions used in preparation of PANI/Ni electrocatalysts on a GC substrate.

\begin{tabular}{cccc} 
Bath & \multicolumn{2}{c}{ Composition } & $\begin{array}{c}\text { Deposition } \\
\text { Potential vs SCE } \\
\text { [V] }\end{array}$ \\
\hline Polyaniline & Aniline & $0.05 \mathrm{M}$ & 0.82 \\
& $\mathrm{H}_{2} \mathrm{SO}_{4}$ & $0.5 \mathrm{M}$ & \\
\hline \multirow{3}{*}{ Nickel } & $\mathrm{NiSO}_{4} \cdot \mathrm{H}_{2} \mathrm{O}$ & $26.2 \mathrm{~g} \mathrm{~L}^{-1}$ & \\
& $\mathrm{H}_{3} \mathrm{BO}_{3}$ & $6.2 \mathrm{~g} \mathrm{~L}^{-1}$ & $-1.45,-1.75,-1.85$ \\
& $\mathrm{H}_{2} \mathrm{SO}_{4}$ & $1.0 \mathrm{mM}$ & \\
\hline
\end{tabular}




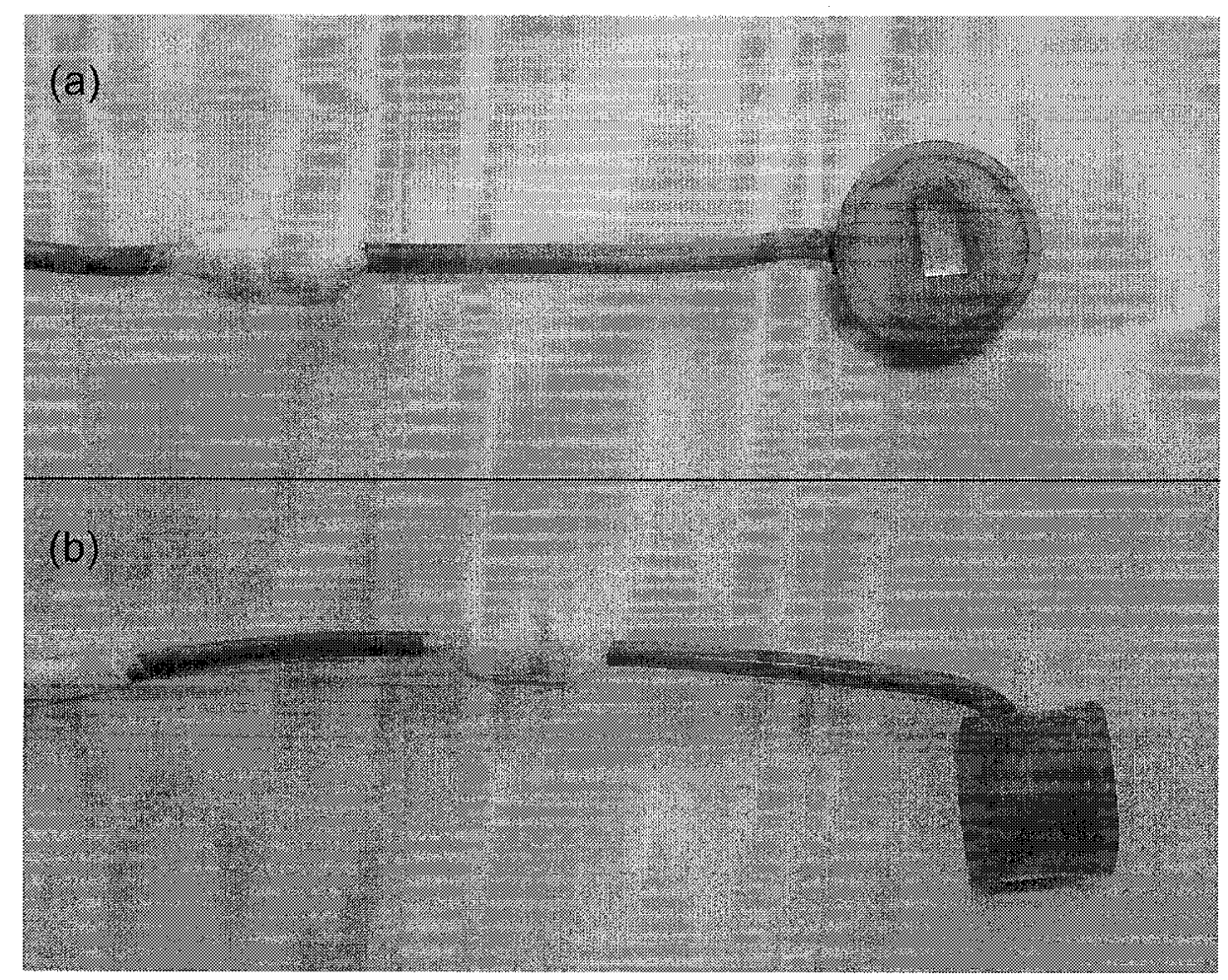

Figure 4.1 Picture of (a) bottom and (b) side view of GC electrode substrate.

\subsubsection{Ni-RVC catalyst}

A potentiostatic electrodeposition method was used to prepare the Ni-RVC electrocatalyst. The specific experimental conditions and baths compositions are outlined in Table 4.2.

Table 4.2 Experimental conditions used in preparation of $\mathrm{Ni}$ catalyst on RVC substrate.

\begin{tabular}{ccccc}
\hline Bath & Composition & $\begin{array}{c}\text { Deposition } \\
\text { Potential vs SCE } \\
{[\mathrm{V}]}\end{array}$ & Deposition time \\
\hline \multirow{4}{*}{ Nickel } & $\mathrm{NiSO}_{4} \cdot \mathrm{H}_{2} \mathrm{O}$ & excess & & \\
& $\mathrm{H}_{3} \mathrm{BO}_{3}$ & $6.2 \mathrm{~g} \mathrm{~L}^{-1}$ & -1.60 & 2 hours \\
& $\mathrm{H}_{2} \mathrm{SO}_{4}$ & $1.0 \mathrm{mM}$ & & \\
\hline
\end{tabular}




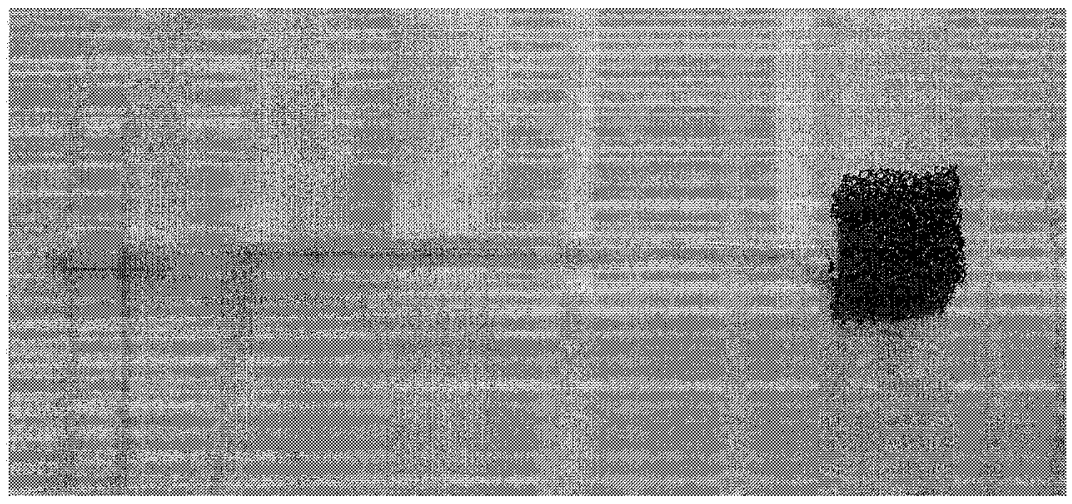

Figure 4.2 Picture of RVC substrate.

\subsubsection{Carbon-supported Ni-nanoparticles}

Nickel nanoparticles were synthesized by reduction of nickel sulfate with sodium borohydride in an aqueous solution containing carbon black. Typically, an aqueous solution of $25 \mathrm{ml}$ was prepared by dissolving $0.657 \mathrm{~g}$ of nickel sulfate. The appropriate mass of carbon black was then added to the solution. The ratio of carbon to nickel in the solution was $60: 40$ by mass. The solution was sonicated for $20 \mathrm{~min}$ to disperse the carbon particles in the solution. The reduction of nickel was initiated by adding $50 \mathrm{ml}$ of $0.1 \mathrm{M}$ sodium borohydride dropwise while sonicating the mixture. The mixture was then left for two hours in the sonic bath to allow the reaction to go to completion. The solids were then filtered, dried, suspended in ethanol, and stored at $5^{\circ} \mathrm{C}$. 


\subsection{Catalyst pretreatment}

After the PANI/Ni and Ni-RVC were prepared, the coated electrode surface was carefully rinsed with a large amount of deionized water in order to remove any residues of bath chemicals and unattached catalyst particles.

For the electrochemical measurements, the desired amount of carbon-supported $\mathrm{Ni}$ nanoparticles $(\mathrm{Ni} / \mathrm{C})$ was placed on the $\mathrm{GC}$ substrate. After evaporation of ethanol, this catalyst layer was fixed on the GC surface by adding $20 \mu \mathrm{l}$ of a Nafion solution on top of the layer, which subsequently polymerized to form a film that prevented detachment of the nanoparticle catalyst.

To characterize the activity of each catalyst, the catalyst-layercovered electrode (working electrode, WE) was placed in the electrochemical cell described in section 4.5. Prior to each set of electrochemical measurements, the working electrode was stabilized at the open circuit potential (OCP) until a steady-state OCP value was obtained.

\subsection{Experimental setup}

A standard three-electrode, one compartment cell was used for electrodeposition of $\mathrm{Ni}$. The counter electrode was a large-area graphite rod. The reference electrode was a commercially available saturated calomel electrode (SCE). For PANI/Ni electrocatalysts, GC was used as the substrate working electrode (surface area $0.27 \mathrm{~cm}^{2}$ ). A RVC substrate 
of volume $1 \mathrm{~cm}^{3}$ was used for the development of the Ni-RVC electrocatalyst.

The electrocatalytic activity of the prepared HER electrocatalysts was studied in $0.5 \mathrm{M} \mathrm{H}_{2} \mathrm{SO}_{4}$ solution in a standard three-electrode, two compartment electrochemical cell (Fig. 4.3). This solution was used in order to simulate the acidic environment in the PEM. The counter electrode was a large-area platinum electrode of high purity $(99.99 \%$, Alfa Aesar), which was degreased by refluxing in acetone, sealed in soft glass, electrochemically cleaned by potential cycling in $0.5 \mathrm{M} \mathrm{H}_{2} \mathrm{SO}_{4}$, and stored in $98 \% \mathrm{H}_{2} \mathrm{SO}_{4}$. During measurements, in order to prevent cathodic reduction of oxygen produced at the anode (counter electrode), the counter electrode was separated from the main cell compartment by a glass frit. The reference electrode was a commercially available saturated calomel electrode (SCE). Three working electrodes were used: (a) a polyaniline/Ni (PANI/Ni) layer, electrodeposited on a glassy carbon (GC) substrate, (b) a carbon black-supported Ni-nanoparticle layer deposited on a GC substrate, and (c) a Ni-coated RVC electrode (Ni-RCV). 

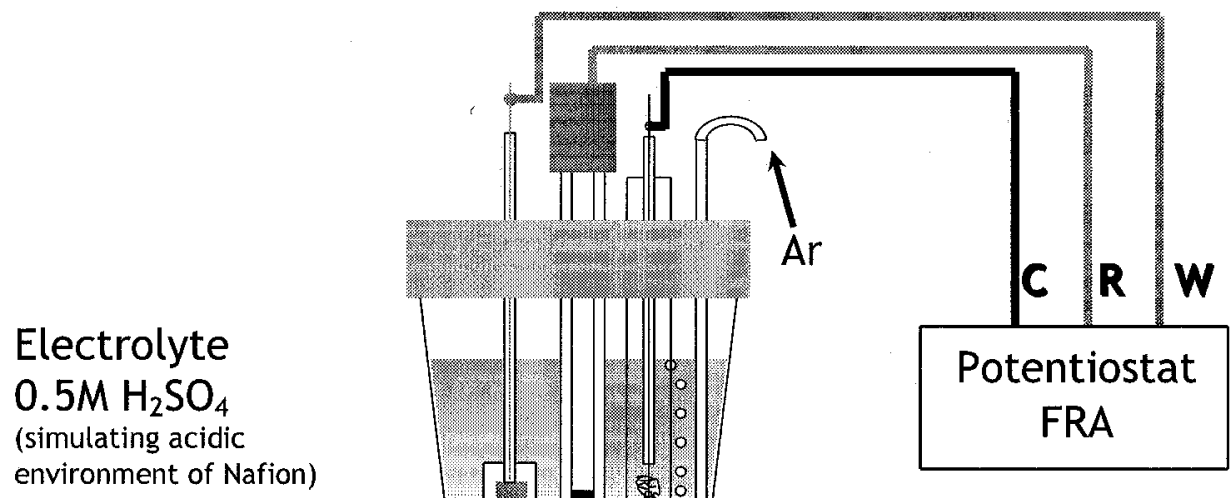

Electrocatalyst (Working Electrode)

Figure 4.3 Experimental setup for electrochemical measurements.

\subsection{Experimental techniques}

Several experimental techniques were used to study the HER electrocatalytic activity of the prepared catalysts, and to characterize their morphology and structural composition.

\subsubsection{Linear Tafel DC polarization}

This technique was used to characterize the electrocatalytic activity of the prepared catalysts. Linear Tafel polarization was performed by polarizing the working electrode (electrocatalyst) from its OCP to the overpotential of $-500 \mathrm{mV}$ at a scan rate of $0.5 \mathrm{mV} \mathrm{s}^{-1}$. All the curves presented in the thesis were corrected for the IR (Ohmic) drop, based on the resistance of the electrolyte obtained from electrochemical impedance spectroscopy (EIS) measurements. 


\subsubsection{Electrochemical impedance spectroscopy (EIS)}

EIS was used to investigate the electrode/electrolyte interface and the corresponding processes that occur at the electrode surface. It provided information on the HER kinetics, mechanisms, electrolyte resistance, surface coverage by hydrogen and surface porosity. EIS measurements were carried out over almost six frequency decades, from $50 \mathrm{kHz}$ to $10 \mathrm{mHz}$. The ac voltage amplitude was $\pm 10 \mathrm{mV}$ peak to peak. The measurements were performed at selected overpotentials in the HER potential region.

An Autolab PGSTAT 30 potentiostat/galvanostat/FRA was used in all the electrochemical measurements.

\subsubsection{Characterization of the catalyst's morphology, particle size, and structural composition}

The morphology of the PANI/Ni coatings was investigated using scanning electron microscopy (SEM) technique. The same GC electrode used in the HER experiments was utilized in SEM experiments. SEM images were taken by a Field Emission Gun Scanning Electron Microscope, FEG-SEM Philips XL30.

Transmission electron microscopy (TEM) was used to obtain the information on the particle size of the synthesized Ni nanoparticles. For the TEM analysis, the carbon-supported $\mathrm{Ni}$ catalyst $(\mathrm{Ni} / \mathrm{C})$ was ultrasonically suspended in ethanol, and a drop of the powder suspension was applied to a carbon film on a Cu TEM grid. 
Information on the structure of the investigated $\mathrm{Ni}$ electrocatalysts was obtained using X-Ray diffraction analysis (XRD) with an X-Ray diffractometer system with a copper rotating anode at $40 \mathrm{kV}$ and $120 \mathrm{~mA}$ (Raiku XRD). The data was exported to Microsoft Excel for analysis and was reported graphically as the diffracted angle vs. intensity dependence. It was compared to a reference database built in Philips PC Identify software. 


\section{CHAPTER 5}

\section{RESULTS AND DISCUSSION}

\subsection{Structural characterization}

$X$-ray diffraction (XRD) was used for structural characterization of the Ni-based electrocatalysts discussed in this thesis. The resulting diffraction patterns are shown in Fig. 5.1.

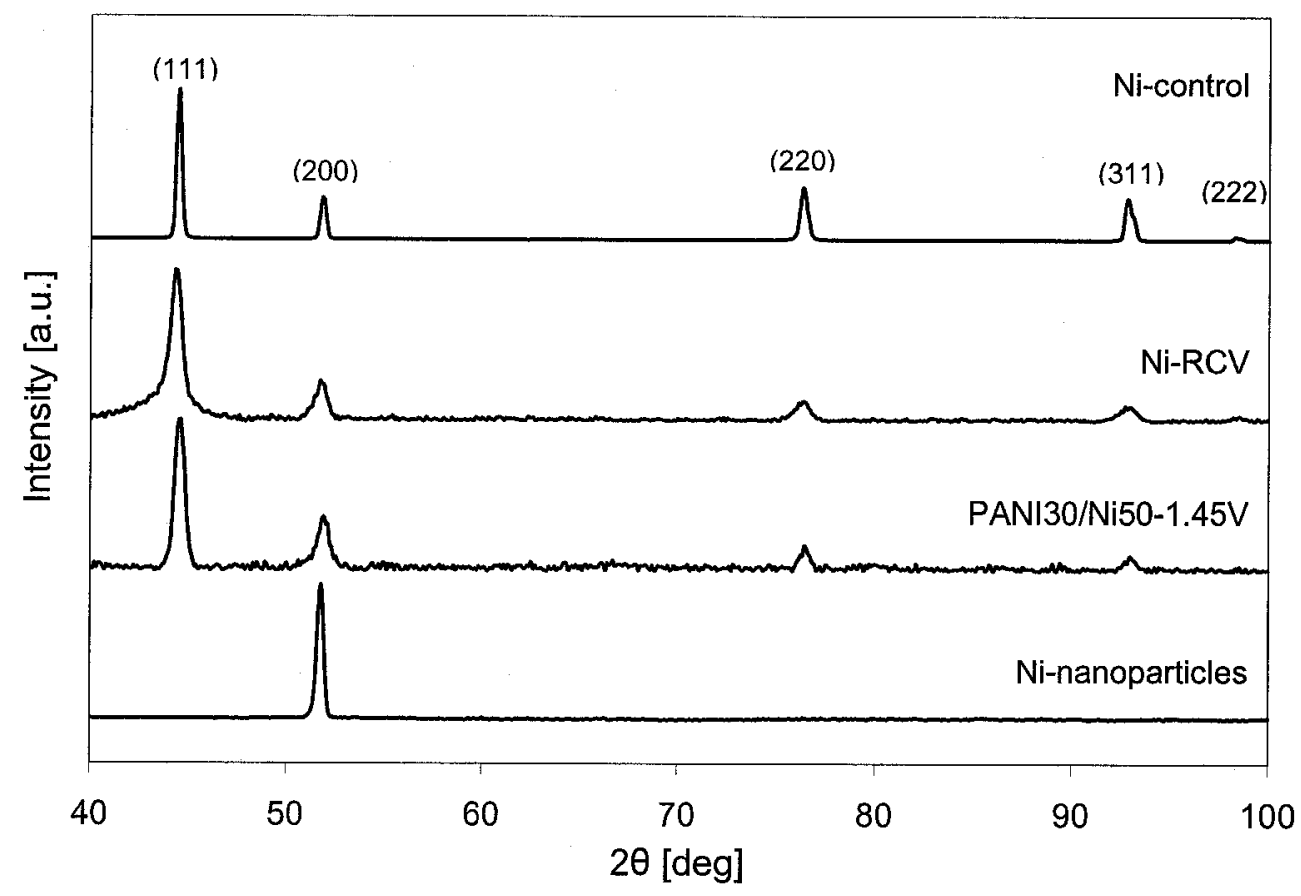

Figure 5.1 X-ray diffraction (XRD) patterns of Ni-based electrocatalysts.

The spectrum recorded on the control surface shows the reflections of the f.c.c. structure of Ni which correspond, in an increasing order of $2 \theta$, to the (111), (200), (220), (311) and (222) reflections [53]. The XRD 
response demonstrates that the control surface is crystalline. On the other hand, the spectrum recorded on Ni-nanoparticles shows only $\mathrm{Ni}(200)$ reflection, while $\mathrm{Ni}(111),(220),(311)$, and (222) reflections are completely absent. The curve demonstrates that the synthesized Ni nanoparticles are crystalline. In contrast, the Ni-RVC and PANI30/Ni50-1.45V electrocatalysts show a small degree of amorphousness, i.e. peak broadening. This difference in crystallinity might be due to the difference in preparation of the electrocatalysts. Namely, the latter two electrocatalysts were prepared by electrochemical deposition, while Ni nanoparticles were synthesized by a chemical method and the control surface was commercially available poly-crystalline Ni. Further, the preparation of the two $\mathrm{Ni}$ layers by the electrochemical method gave a similar XRD response, characterized in an increasing order of $2 \theta$ by the (111), (200), (220), (311) and (222) reflections of the f.c.c. structure of Ni. Thus, the two electrochemically prepared layers are structurally similar to the control surface, all three of which are of a poly-crystalline structure, while the $\mathrm{Ni}$ nanoparticle layer is of a single-crystalline structure characterized by the (200) orientation.

\subsection{Morphology of electrodes}

Scanning electron microscopy (SEM) was used to examine the surface morphology of the control surface (Ni plate), PANI matrix, PANI/Ni electroacatalystic layers, and of the Ni-RVC electrocatalyst. Transmission 
electron microscopy (TEM) was used to obtain information on the structure (particle size) of the Ni nanoparticle layer.

The control surface (Fig. 5.2a) shows a relatively homogeneous and smooth morphology, characterized by a relatively small roughness. Thus, the control electrocatalyst can be considered to have a quazi-2D surface morphology.

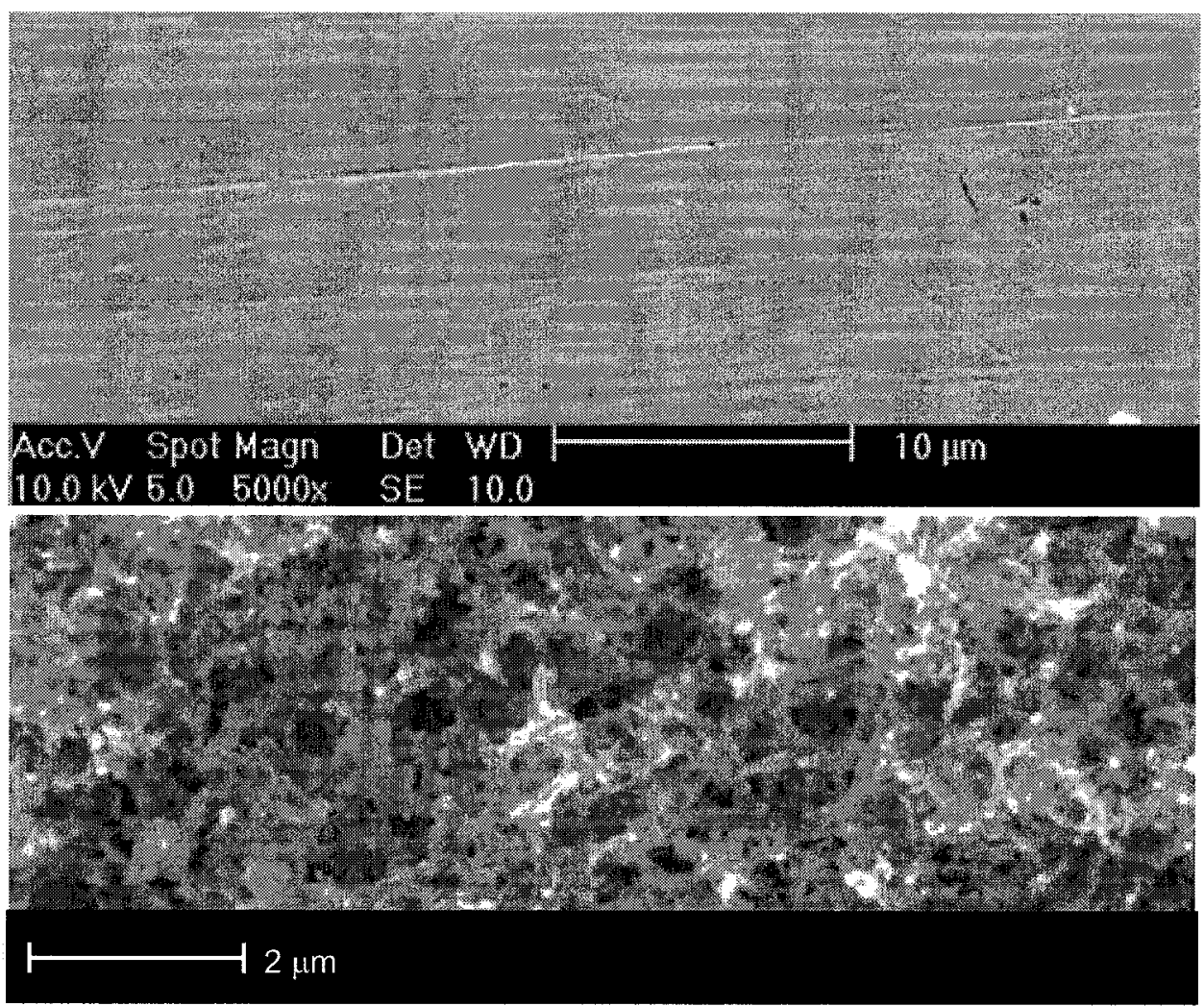

(a) up / (b) down

Figure 5.2 SEM images showing the surface morphology of (a) the control surface and (b) polyaniline (PANI) electrodeposited on a GC substrate.

The PANI matrix presented in Fig. $5.2 \mathrm{~b}$ has a highly fibrilar, branched, and porous 3D structure. Such morphology could thus enable formation of a 3D Ni layer, which can offer both an increased surface area 
and number of electrocatalytically active sites for the HER. This is confirmed by Fig 5.3, which shows the image of an electrocatalyst layer produced by electrodeposition of $\mathrm{Ni}$ at $-1.45 \mathrm{~V}$ on a pre-deposited PANI layer. The electrodeposition time of the PANI layer was 30 minutes, and of the Ni layer 50 minutes (as already quoted in Section 4.3.1, this catalyst is denoted as PANI30/Ni50-1.45V).

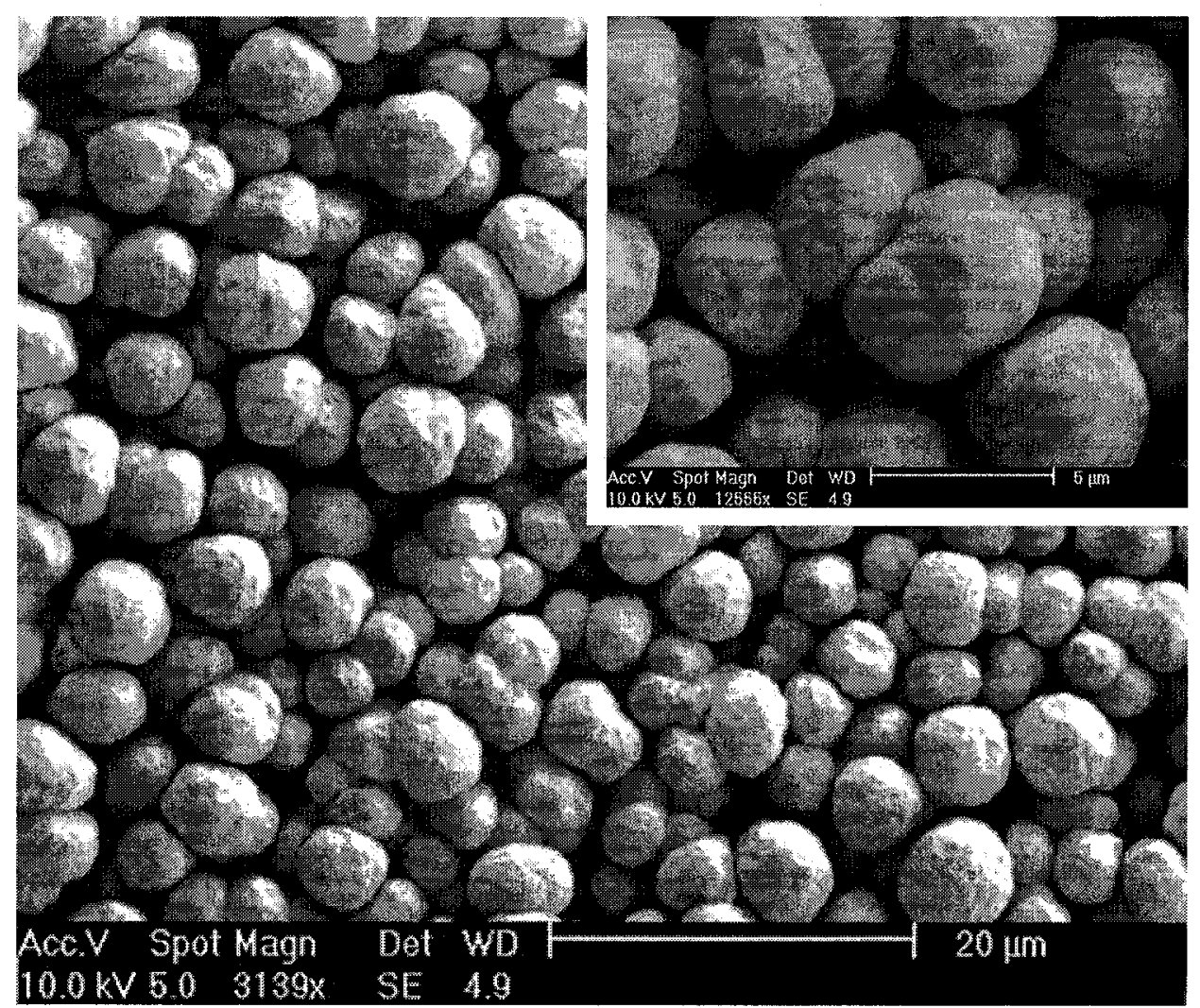

Figure 5.3 SEM image of an electrocatalyst layer made by electrodeposition of $\mathrm{Ni}$ for $50 \mathrm{~min}$ at $-1.45 \mathrm{~V}$ on a pre-deposited PANI layer formed on a GC substrate during the period of $30 \mathrm{~min}$.

Indeed, the formed PANI30/Ni50-1.45 electrocatalyst is a 3D layer composed of spherical Ni particles. An average diameter of the particles is $4.6 \pm 0.7 \mu \mathrm{m}$, and their size distribution is quite narrow. The structure of the 
layer is porous. The image of the PANI30/Ni50-1.45V electrocatalyst does not show any presence of PANI residues incorporated inside the layer, or attached to Ni particles. Considering the highly fibrous morphology of the pre-deposited PANI layer (Fig. 5.2b), it is quite surprising to see the spherical structure of the produced Ni layer. Presently, it is not clear to us what the origin of such a large difference in the observed structure/morphology transformation is, but the influence of hydrophobic/hydrophillic, structural (fibrous), or surface charge distribution properties of the pre-deposited PANI layer could be one of the possible effects.

Figs. 5.4 shows SEM images of PANI30/Ni50 electrocatalysts formed at various $\mathrm{Ni}$ electrodeposition potentials. 

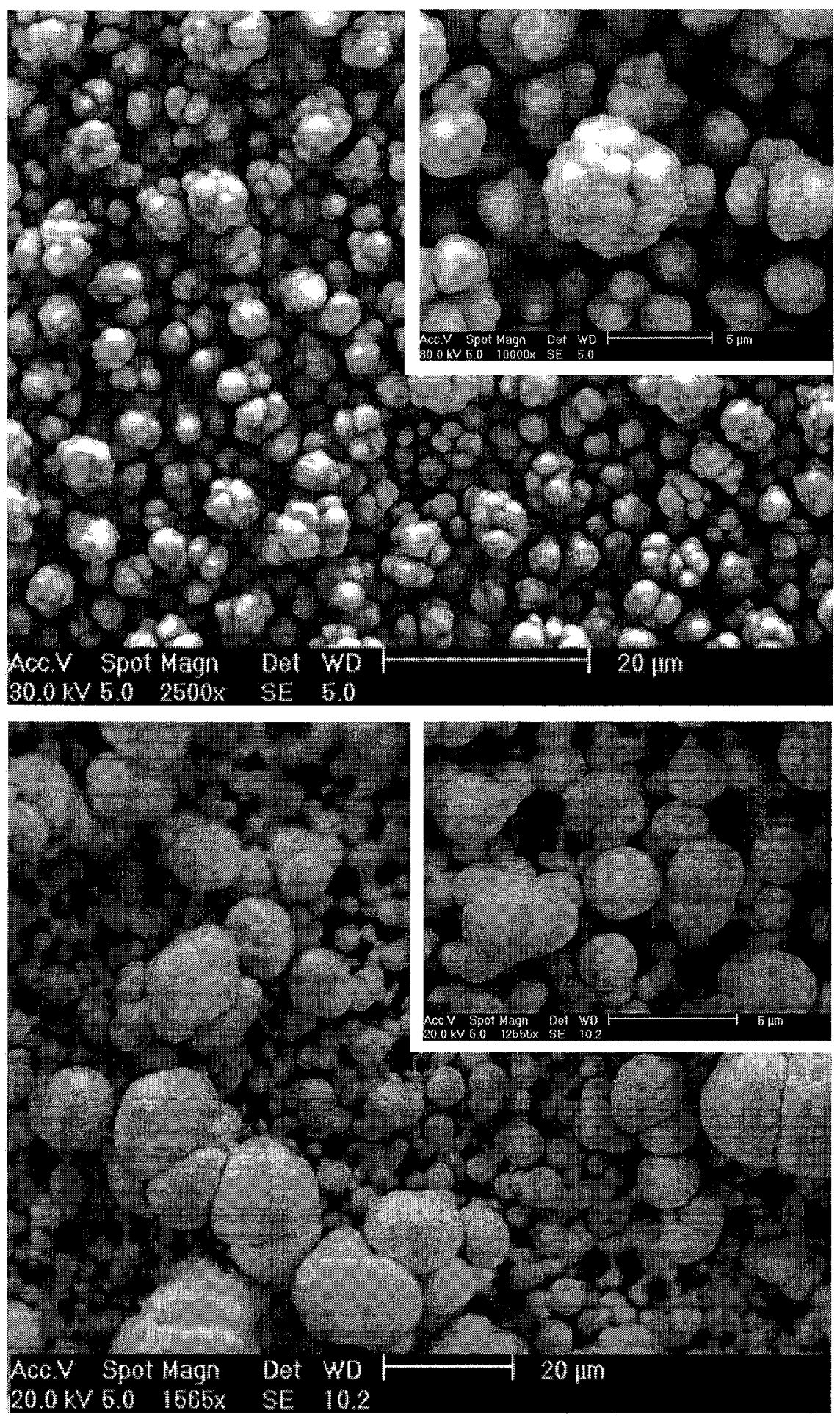

(a) up / (b) down

Figure 5.4 SEM images of an electrocatalyst layer made by electrodeposition of $\mathrm{Ni}$ for $50 \mathrm{~min}$ at (a) $-1.75 \mathrm{~V}$ and (b) $-1.85 \mathrm{~V}$ on a predeposited PANI layer formed on a GC substrate during the period of 30 $\min$. 
It is evident that with a decrease in $\mathrm{Ni}$ electrodeposition potential to more negative values, the $\mathrm{Ni}$ particle size also decreases. Thus, by decreasing the $\mathrm{Ni}$ electrodeposition potential from $-1.45 \mathrm{~V}$ to $-1.75 \mathrm{~V}$, the $\mathrm{Ni}$ particle size decreases from $4.6 \pm 0.7$ to $2.7 \pm 0.7 \mu \mathrm{m}$. A further decrease in particle size down to $2.3 \pm 1.0 \mu \mathrm{m}$ (excluding the large agglomerates visible on the micrograph) was obtained by lowering the $\mathrm{Ni}$ electrodeposition potential to $-1.85 \mathrm{~V}$, but the corresponding particle size distribution is relatively large. The dependence between the $\mathrm{Ni}$ electrodeposition potential and particle size yields a linear relationship $\left(R^{2}=0.994\right)$ in the potential region investigated, but this linear relationship is not completely reliable since only three experimental points were taken into account. Nevertheless, the presented results demonstrate that by controlling the $\mathrm{Ni}$ electrodeposition potential, it is also possible to control the Ni particle size, and thus the surface area available for the HER. This was confirmed by $d c$ linear polarization measurements, discussed later in the text (Section 5.3.1.3)

Fig. 5.5 displays a SEM image of the Ni-RVC electrode. The porosity of the RVC substrate used is 45 pores per inch (45PPI). 


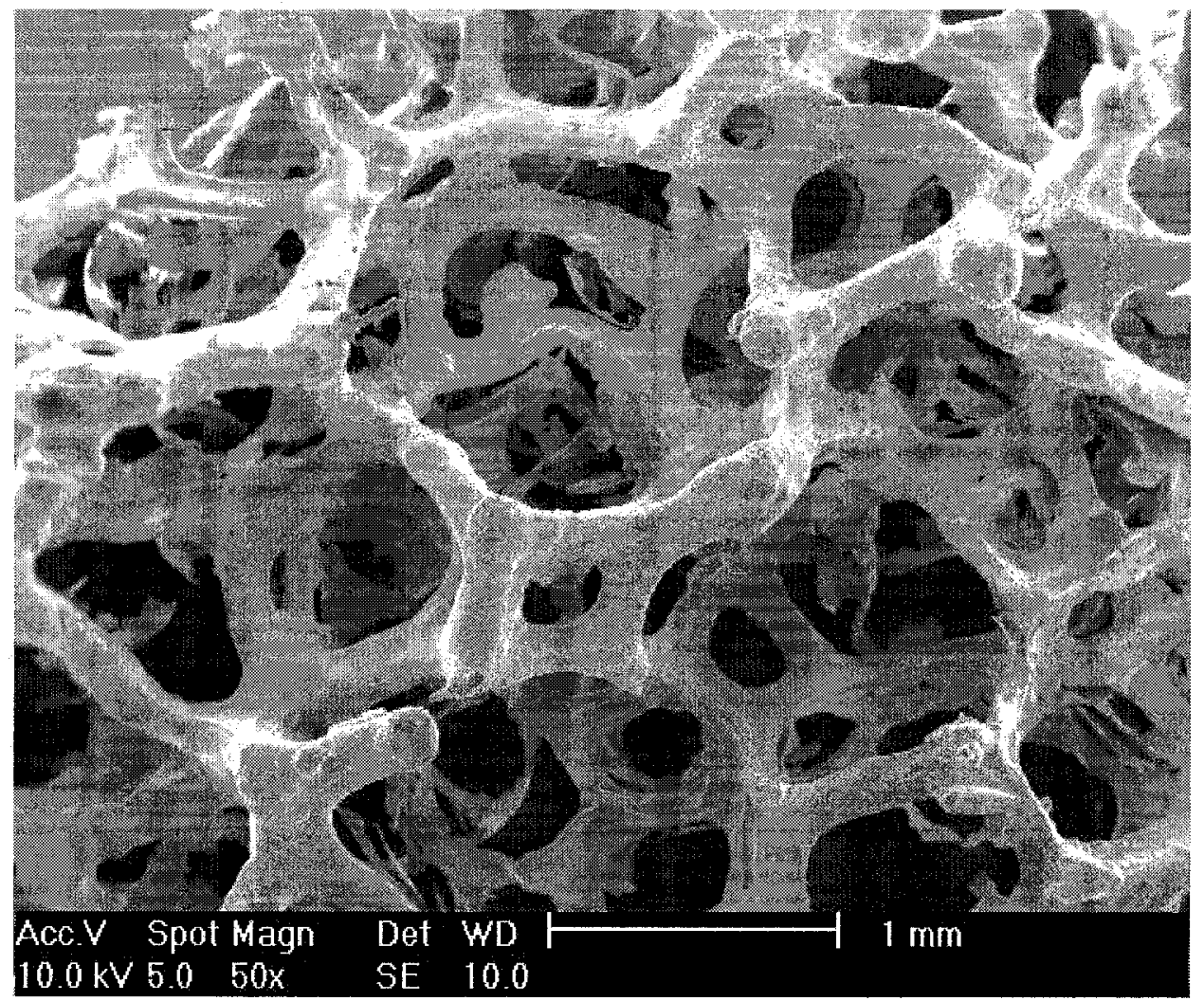

Figure 5.5 SEM image showing the morphology of the Ni-RVC electrocatalyst.

The image shows that the Ni layer is uniformly deposited on the RVC surface. However, using the RVC preparation and Ni electrodeposition method described in the experimental section, it was possible to coat only ca. $3 \mathrm{~mm}$ of the outer RVC surface with $\mathrm{Ni}$, leaving the inner portion of the RVC cube Ni-free. This is most likely because the RVC is hydrophobic, which prevented wetting of the inner portion of the RVC cube with a $\mathrm{Ni}-$ electrodeposition electrolyte. Even the electrochemical pre-treatment of RVC in sulfuric acid did not give satisfactory results. Thus, the optimum 45PPI RVC substrate dimensions should not be larger then 
$0.6 \times 0.6 \times 0.6 \mathrm{~cm}^{3}$. For larger dimensions, RVC with larger pore dimensions should be used.

Similarly to the use of Pt-based nanoparticles to prepare electrocatalysts for hydrogen and direct methanol fuel cells, the use of $\mathrm{Ni}$ nanoparticles to prepare HER electrocatalytic electrode layers for hydrogen generators should also result in an increased electrocatalytic activity of the hydrogen evolution electrode, when compared to quazi-2D electrodes. While synthesis and characterization of Pt-based nanoparticles has extensively been reported in literature [54-59], synthesis of $\mathrm{Ni}$ nanoparticles has rarely been reported [60-68]. To the best of our knowledge, no studies on synthesis of carbon-supported Ni nanoparticles, or use of unsupported $\mathrm{Ni}$ nanoparticles as electrocatalysts for hydrogen production or any other electrochemical process/reaction have been published. Fig. 5.6 shows a TEM image of Ni nanoparticles anchored on a Vulcan carbon support. The average diameter of the $\mathrm{Ni}$ particles is $27 \pm 6 \mathrm{~nm}$. 


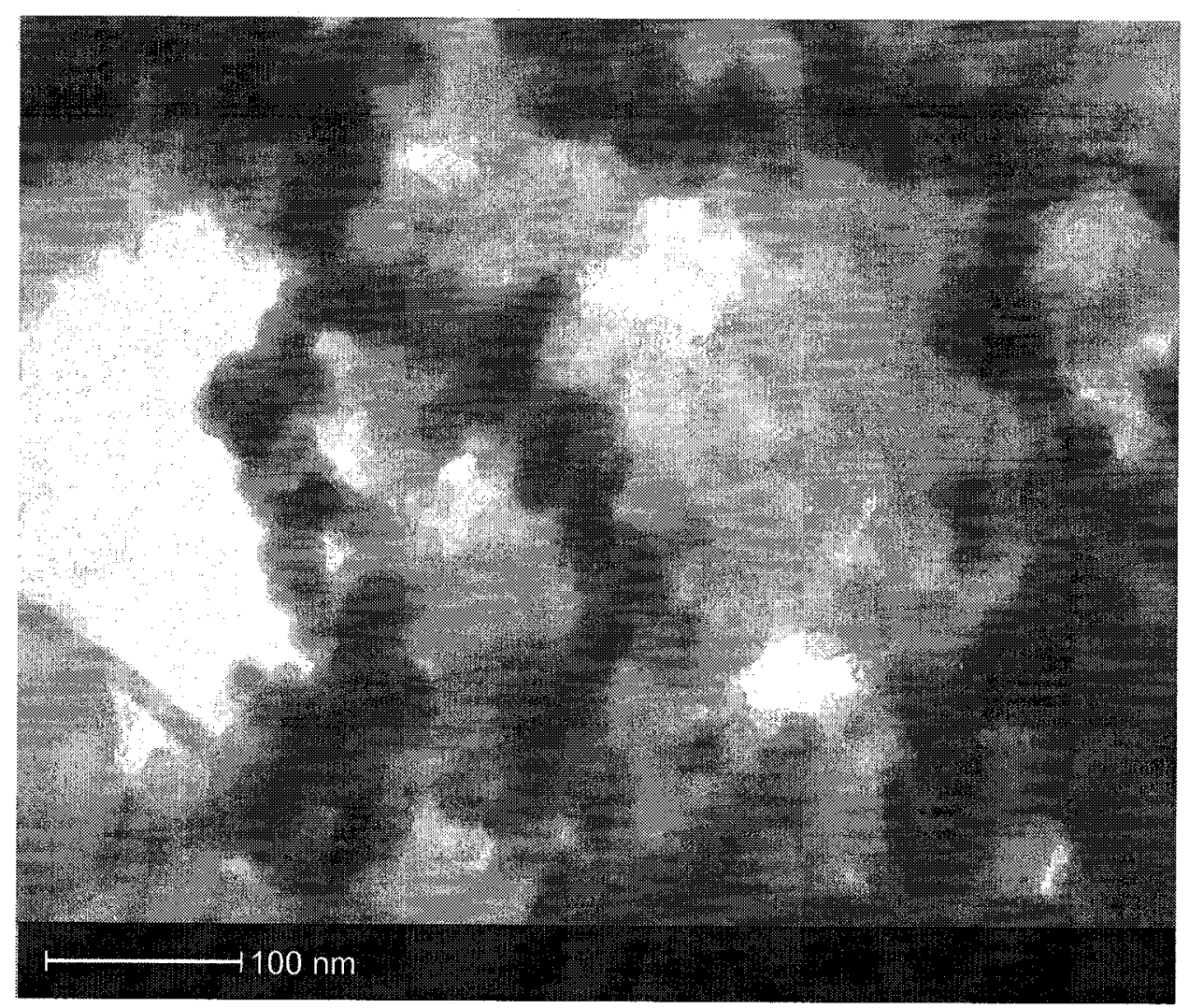

Figure 5.6 TEM image showing Ni nanoparticles on a Vulcan carbon support synthesized at room temperature.

However, their spatial distribution on the carbon surface is not uniform. In addition, the image shows that the particles form agglomerates. Optimization of $\mathrm{Ni}$ nanoparticles production, their characterization and HER activity is the proposed future work in our laboratory, and preliminary results are only shown here. 


\subsection{Linear $d c$ polarization measurements}

In order to investigate the electrocatalytic activity of the prepared $\mathrm{Ni}$ layers, Tafel linear polarization measurements were made, and the corresponding electrochemical parameters (Tafel slope and exchange current density) were derived from the recorded curves.

\subsubsection{PANI/Ni electrocatalyst layers}

\subsubsection{Influence of Ni deposition time}

Fig 5.7 shows the selected linear polarization curves recorded on the $\mathrm{PANI} / \mathrm{Ni}$ electrocatalysts formed by electrodepositing $\mathrm{Ni}$ for various length of times, while the PANI pre-electrodeposition time was kept constant. All the curves show a classical Tafelian behavior, which clearly demonstrates that the HER on all the electrocatalysts is a purely kinetically controlled reaction in the potential region investigated. 


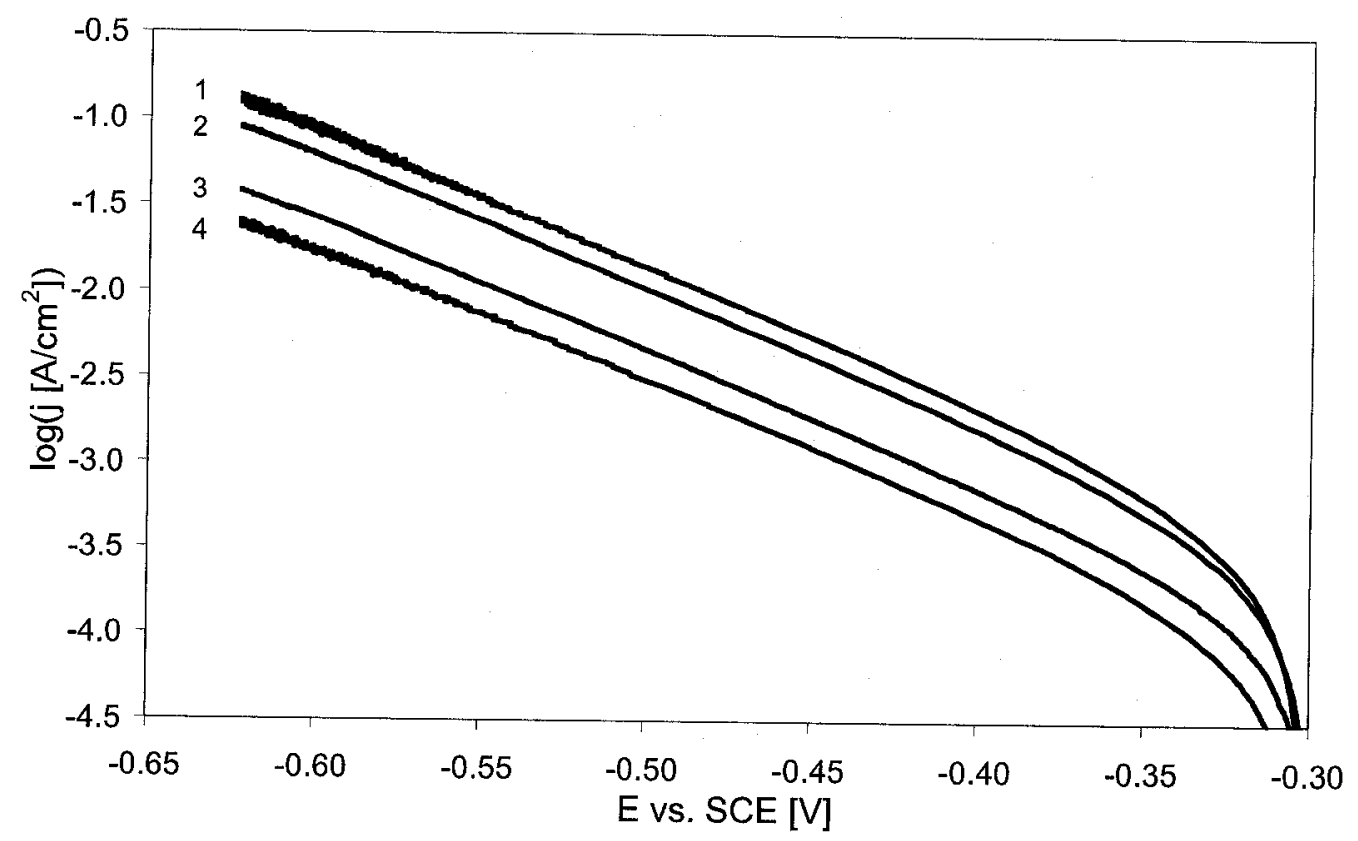

Figure 5.7 Linear polarization curves showing the influence of $\mathrm{Ni}$ deposition time. The curves were recorded on: (1) PANI30/Ni50, (2) PANI30/Ni40, (3) PANI30/Ni20 and (4) PANI30/Ni60. Scan rate $=0.5$ $\mathrm{mVs}^{-1}$. The curves were corrected for the IR-drop. $\mathrm{Ni}$ was electrodeposited at $-1.45 \mathrm{~V}$.

An average value of the Tafel slope determined from the presented curves is $120 \pm 4 \mathrm{mV}$ decade $^{-1}$. According to the general model of the HER mechanisms in an acidic medium [21,69, 70] this value of Tafel slopes indicates that the Volmer reaction step (Eq. 2.5), i.e. adsorption of hydrogen on $\mathrm{Ni}$ to form $\mathrm{Ni}-\mathrm{H}_{\text {ads }}$, is the rate determining step. For this step, the theoretical value of Tafel slope is $116 \mathrm{mV}$ decade $^{-1}$ at $25^{\circ} \mathrm{C}$.

The purpose of doing the experiments presented in Fig. 5.7 was to investigate the influence of $\mathrm{Ni}$ electrodeposition time on the resulting activity of the PANI/Ni electrocatalysts in the HER. Since the same metal 
(Ni) was used to prepare all the electrocatalysts, the observed difference in electrocatalytic activity should thus only be related to the difference in the electrochemically active surface area available for the HER, i.e. the difference in the number of electroactive sites available for the reaction.

Fig. 5.7 shows that the electrocatalytic activity of the PANI/Ni electrocatalysts increases with an increase in Ni deposition time. Namely, with an increase in electrodeposition time at constant electrodeposition potential, the growth rate of $\mathrm{Ni}$ particles decreases, which is due to an increase in their surface area and subsequent decrease in mass-transport rate. However, at the same time, the nucleation and growth of new spherical particles occurs in parallel, resulting in an increase in the number of particles formed on the surface (density). Hence, the overall Ni surface coverage increases with $\mathrm{Ni}$ deposition time. The highest $\mathrm{Ni}$ surface coverage, and thus the highest electrocatalytic activity was obtained when $\mathrm{Ni}$ was deposited for 50 min (Fig. 5.7, curve 1). Further increase in $\mathrm{Ni}$ deposition time resulted in a decrease in the electrocatalytic activity of the electrocatalyst. This is because at high $\mathrm{Ni}$ deposition times, the formed $\mathrm{Ni}$ particles agglomerate forming a quazi-2D Ni layer, thus reducing the active surface area available for the HER. Hence, the HER activity versus $\mathrm{Ni}$ electrodeposition time dependence seems to be parabolic, yielding an electrocatalytic activity maximum (see Fig. 5.13 and the corresponding discussion in Section 5.3.1.4). 


\subsubsection{Influence of PANI deposition time}

Fig. 5.8 shows a set of linear polarization curves recorded on various PANI/Ni electrocatalysts prepared by pre-electrodepositing PANI for various length of time, while the subsequent $\mathrm{Ni}$ electrodeposition time was kept constant.

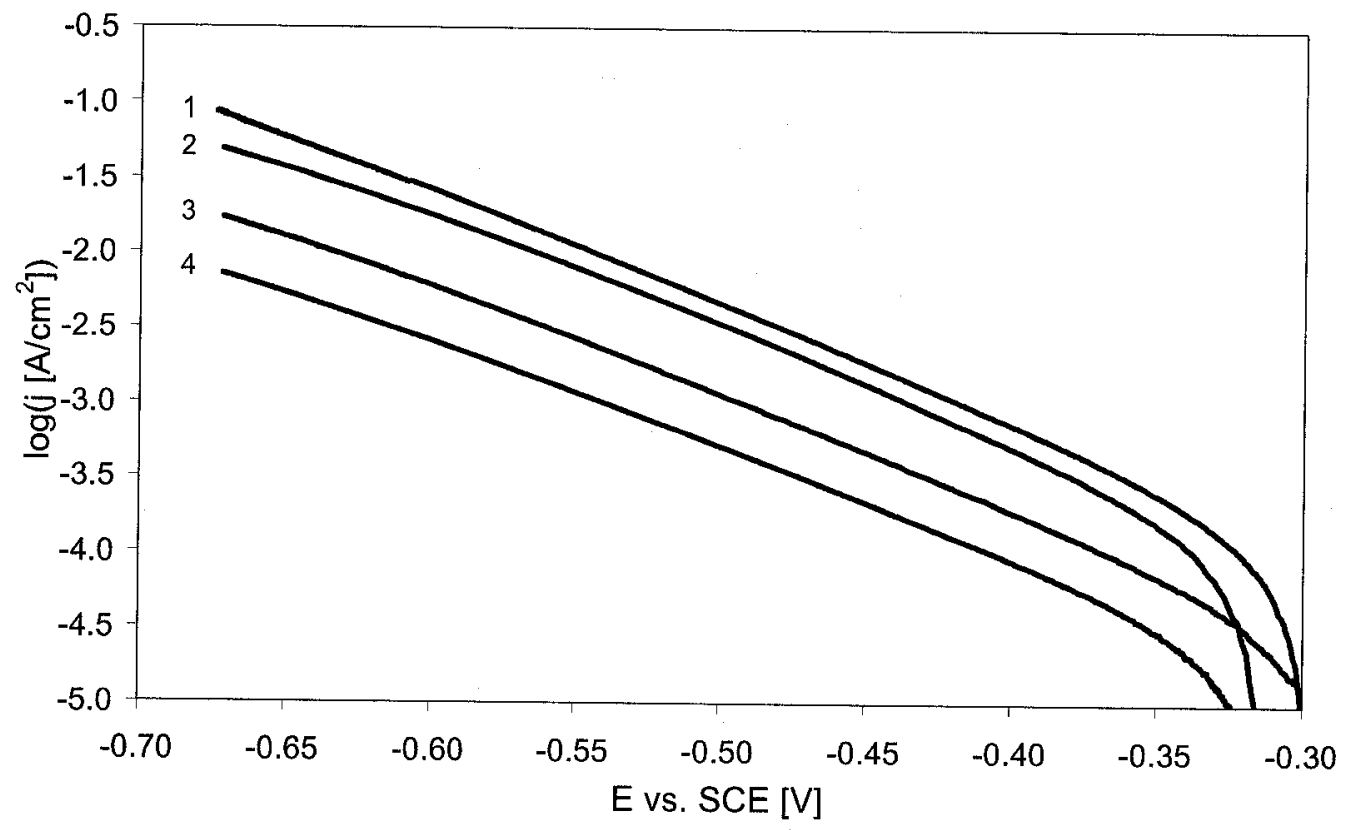

Figure 5.8 Linear polarization curves showing the influence of PANI deposition time. The curves were recorded on: (1) PANI30/Ni20, (2) PANI40/Ni20, (3) PANI10/Ni20 and (4) PANI6/Ni20. Scan rate $=0.5 \mathrm{mV} \mathrm{s}^{-}$ 1. The curves were corrected for the IR-drop. Ni was deposited at $-1.45 \mathrm{~V}$.

The purpose of doing these experiments was to investigate the influence of PANI deposition time on the resulting activity of the PANI/Ni electrocatalyst in the HER. The results show that the PANI deposition time does not have any influence on the HER reaction mechanism, since all the curves show a similar Tafel slope value $\left(127 \pm 6 \mathrm{mV}_{\text {decade }}{ }^{-1}\right)$. However, it 
is obvious that the PANI deposition time significantly influences the electrocatalytic activity of the PANI/Ni electrocatalyst. It seems that in order to produce a thicker Ni particle layer, i.e. more Ni particles and thus a larger surface area available for the HER, a thicker PANI film is also needed. However, a too long PANI deposition time, relative to the $\mathrm{Ni}$ deposition time, results in a decrease in the electrocatalytic activity in the HER. This is most probably because at long (relative to Ni) PANI deposition times, Ni remains "arrested" inside the thicker PANI layer, which results in partial physical blockage (insulation) of the Ni particle surface, thus decreasing the electrocatalytically active surface area available for the HER. In fact, at a higher (and optimum) Ni-to-PANI deposition time (PANI50/Ni30-1.45, Fig. 5.3), PANI almost completely gets removed from the layer, thus 'freeing' the Ni particle surface area for the HER. Similarly to the dependence discussed in the previous section, the HER activity versus PANI electrodeposition time dependence appears to also be parabolic (see Fig. 5.13 and the corresponding discussion Section 5.3.1.4).

\subsubsection{Influence of Ni deposition potential}

The influence of $\mathrm{Ni}$ deposition potential on the resulting electrocatalytic activity of the PANI30/Ni50 electrocatalyst (which has been in the previous sections shown to be the most HER active layer) was also investigated, and the corresponding results are presented in Fig. 5.9. 


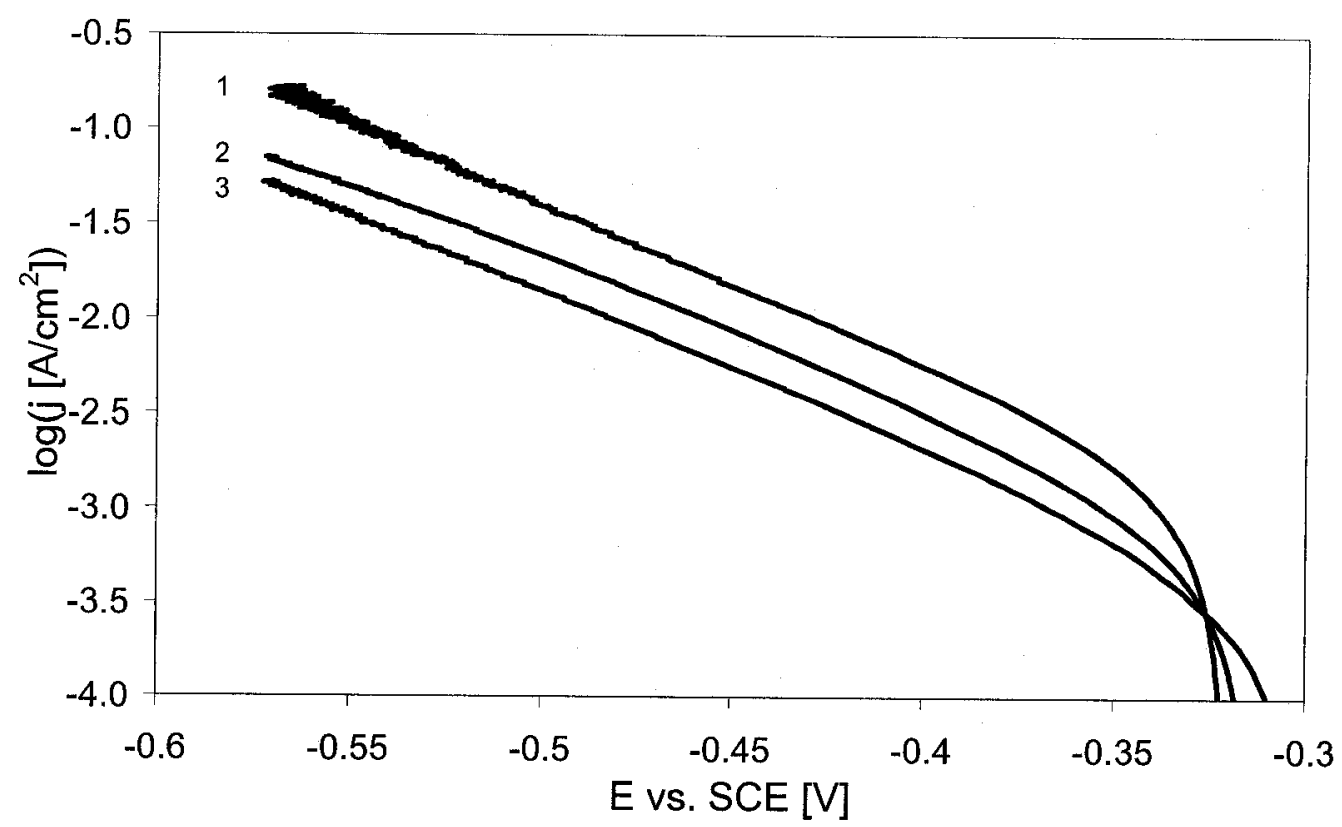

Figure 5.9 Linear polarization curves showing the influence of $\mathrm{Ni}$ electrodeposition potential. The curves were recorded on PANI30/Ni50 formed by electrodeposition of $\mathrm{Ni}$ at (1) $-1.85 \mathrm{~V},(2)-1.75 \mathrm{~V}$ and (3) -1.45 $V$. Scan rate $=0.5 \mathrm{mV} \mathrm{s}^{-1}$. The curves were corrected for the IR-drop.

The Tafel curves demonstrate that the HER mechanism is the same on all three electrocatalysts (Tafel slope is $115 \pm 2 \mathrm{mV}$ decade $^{-1}$ ). However, the corresponding electrocatalytic activity increases with an increase in the $\mathrm{Ni}$ deposition overpotential. Namely, with an increase in $\mathrm{Ni}$ electrodeposition overpotential, the $\mathrm{Ni}$ nucleation rate and the surface density of formed Ni nuclei also increases, while the particle growth rate decreases. This results in the formation of a Ni particle layer characterized by an increased particle surface density and decreased particle diameter, as already discussed in Section 5.2 (Fig. 5.3 and Fig. 5.4). This, in turn, 
results in an increase in the active surface area of the electrocatalyst, and hence an increased HER current density (Fig. 5.9).

\subsubsection{Relative comparison of PANI/Ni electrocatalysts}

Fig. 5.10 shows the HER behavior of the investigated PANI/Ni electrocatalysts where $\mathrm{Ni}$ was electrodeposited for $20 \mathrm{~min}$. The bar chart shows the HER current density measured at potential of $-0.35 \mathrm{~V}$, which is in the overpotential region relevant for the operation of a hydrogen generator.

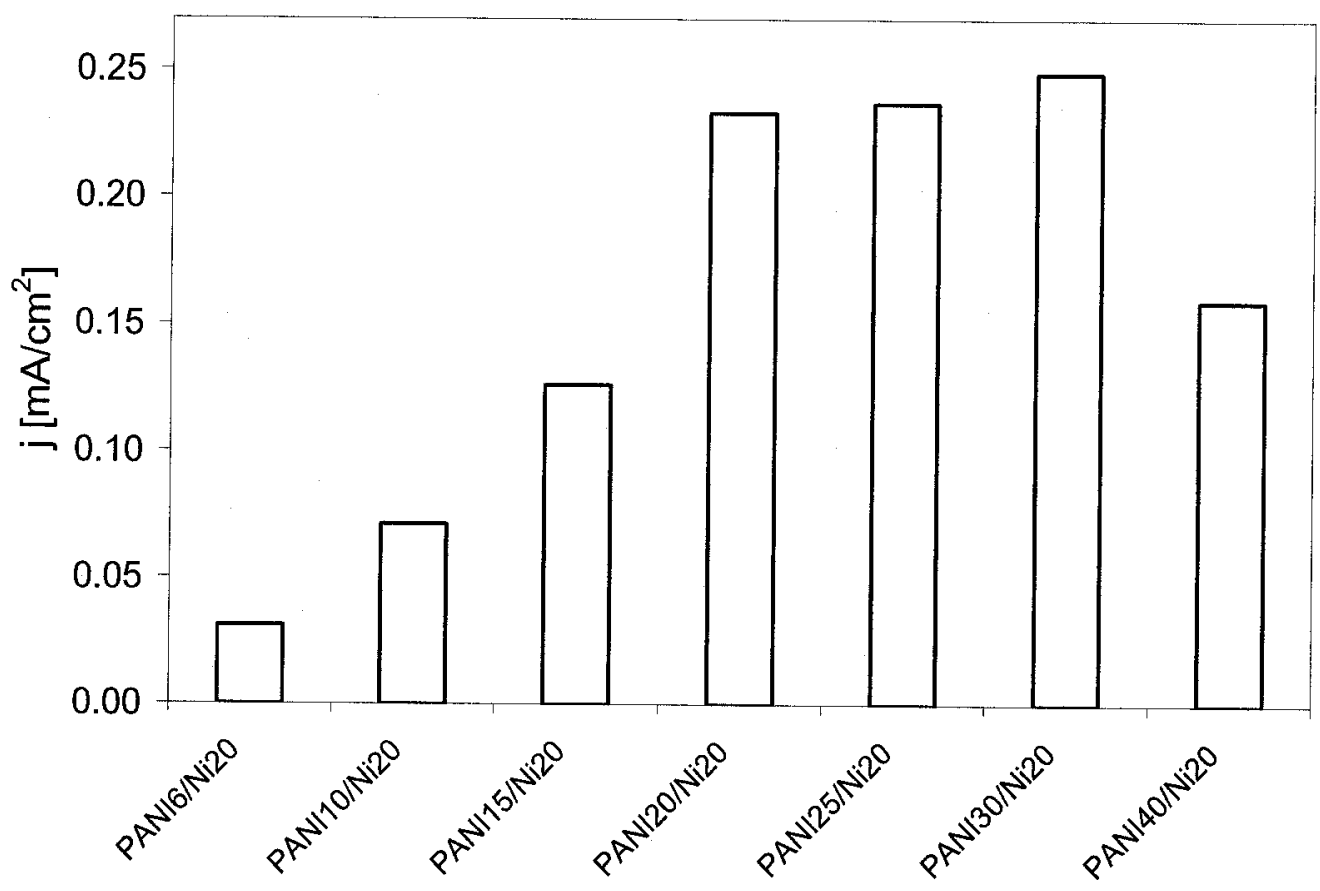

Figure 5.10 HER electrocatalytic activity of PANI/Ni electrocatalysts measured at $-0.35 \mathrm{~V}$. The bars show the influence of PANI electrodeposition time.

The figure clearly demonstrates the influence of PANI deposition time on the resulting electrocatalytic activity in the HER. As mentioned before, 
a thicker PANI layer is required to produce a larger number of Ni particles, and thus a larger Ni particle surface area available for the HER. It seems that the optimum relative thickness is obtained when PANI is deposited for $30 \mathrm{~min}$. At too long PANI-to-Ni deposition times, the formed $\mathrm{Ni}$ layer remains "arrested" inside the thicker PANI layer, which results in partial physical blockage (insulation) of the Ni particle surface, thus decreasing the electrocatalytically active surface area available for the HER.

Fig. 5.11 summarizes the HER behavior of the investigated PANI/Ni electrocatalysts where PANI was electrodeposited for $30 \mathrm{~min}$. The bar chart shows the HER current density measured at potential of $-0.35 \mathrm{~V}$.

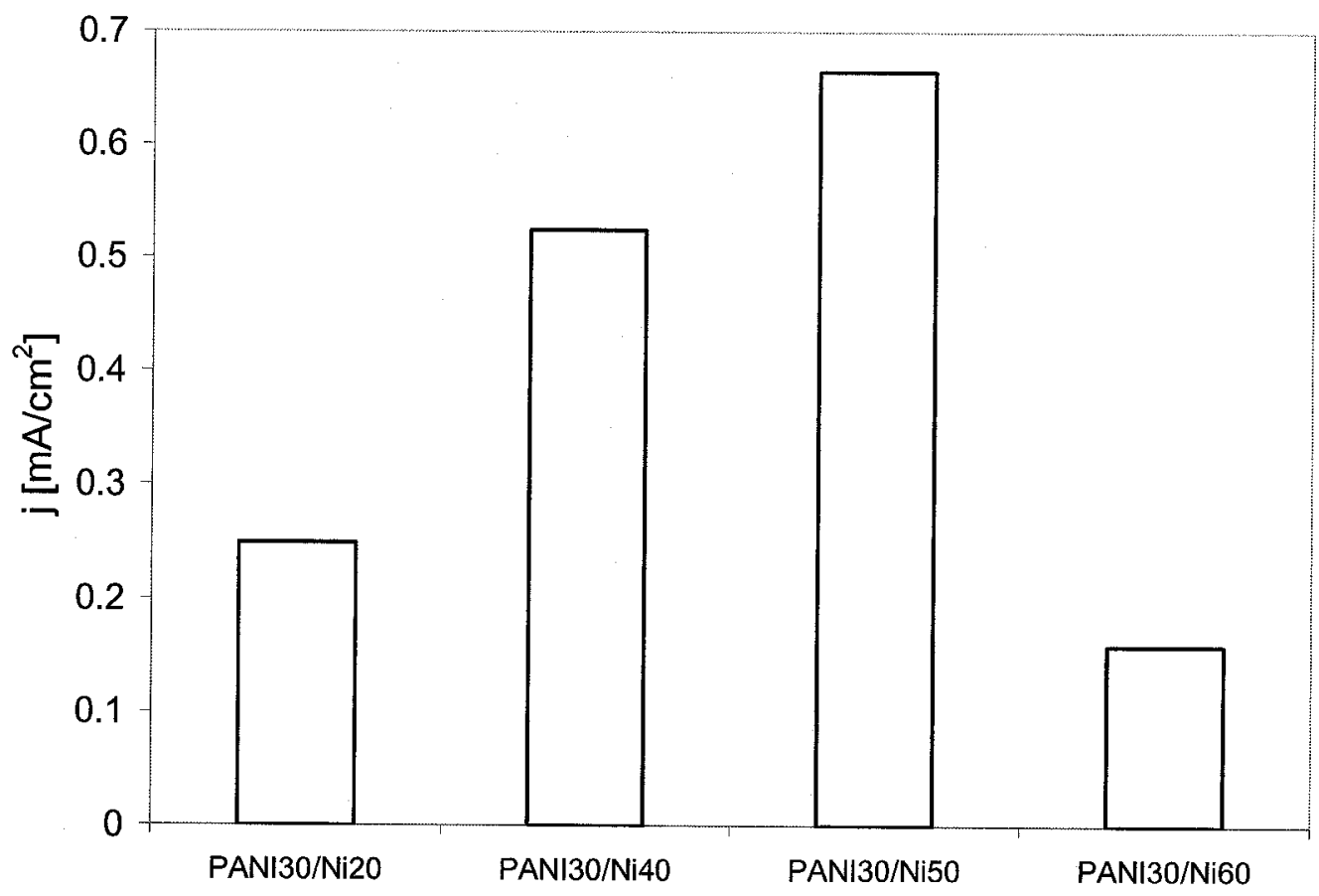

Figure 5.11 HER electrocatalytic activity of PANI/Ni electrocatalysts measured at $-0.35 \mathrm{~V}$. The bars show the influence of $\mathrm{Ni}$ electrodeposition time. 
The figure shows the influence of $\mathrm{Ni}$ deposition time on the resulting electrocatalytic activity in the HER. As mentioned earlier, the electrocatalytic activity of the PANI/Ni electrocatalysts increases with an increase in $\mathrm{Ni}$ deposition time. At too long Ni-to-PANI deposition times, a quazi-2D Ni layer is formed, which results in a decrease in the activity of the electrocatalyst, as already discussed in Section 5.3.1.1.

PANI30/Ni50 is the most HER active electrocatalysts from these two groups. However, the results in Fig. 5.12 below demonstrate that its activity can be further improved if $\mathrm{Ni}$ is electrodeposited at larger $\mathrm{Ni}$ electrodeposition overpotentials, which enables the formation of $\mathrm{Ni}$ particles of a smaller diameter, thus effectively increasing the surface area available for the HER. 


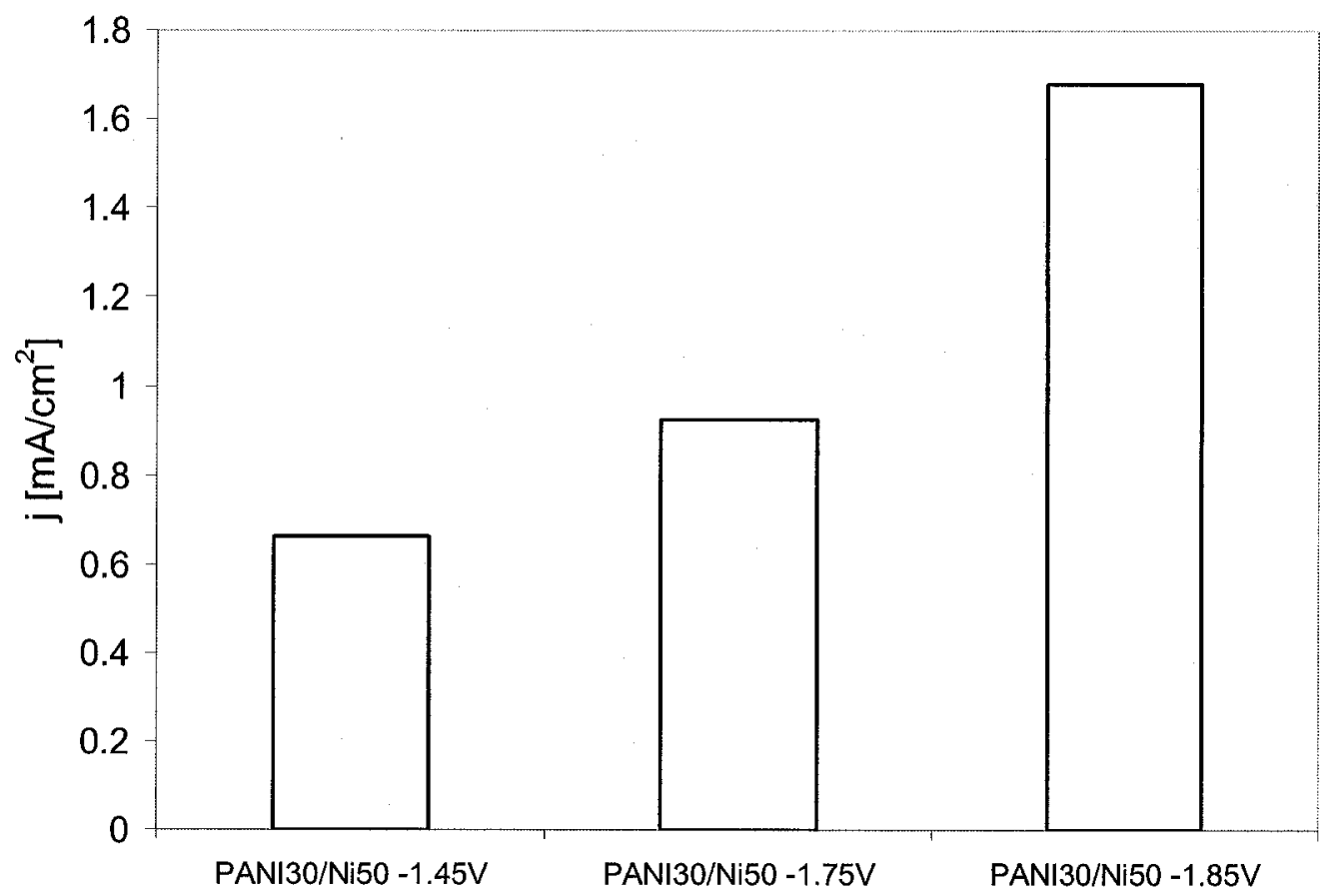

Figure 5.12 HER electrocatalytic activity of PANI30/Ni50 electrocatalysts measured at $-0.35 \mathrm{~V}$. The bars show the influence of $\mathrm{Ni}$ electrodeposition potential.

Fig. 5.13 summarizes the HER behavior of all the investigated PANI/Ni electrocatalysts. The figure clearly demonstrates the influence of PANI and Ni deposition time (white and grey bars, respectively) and potential (black bars) on the resulting electrocatalytic activity in the HER. 


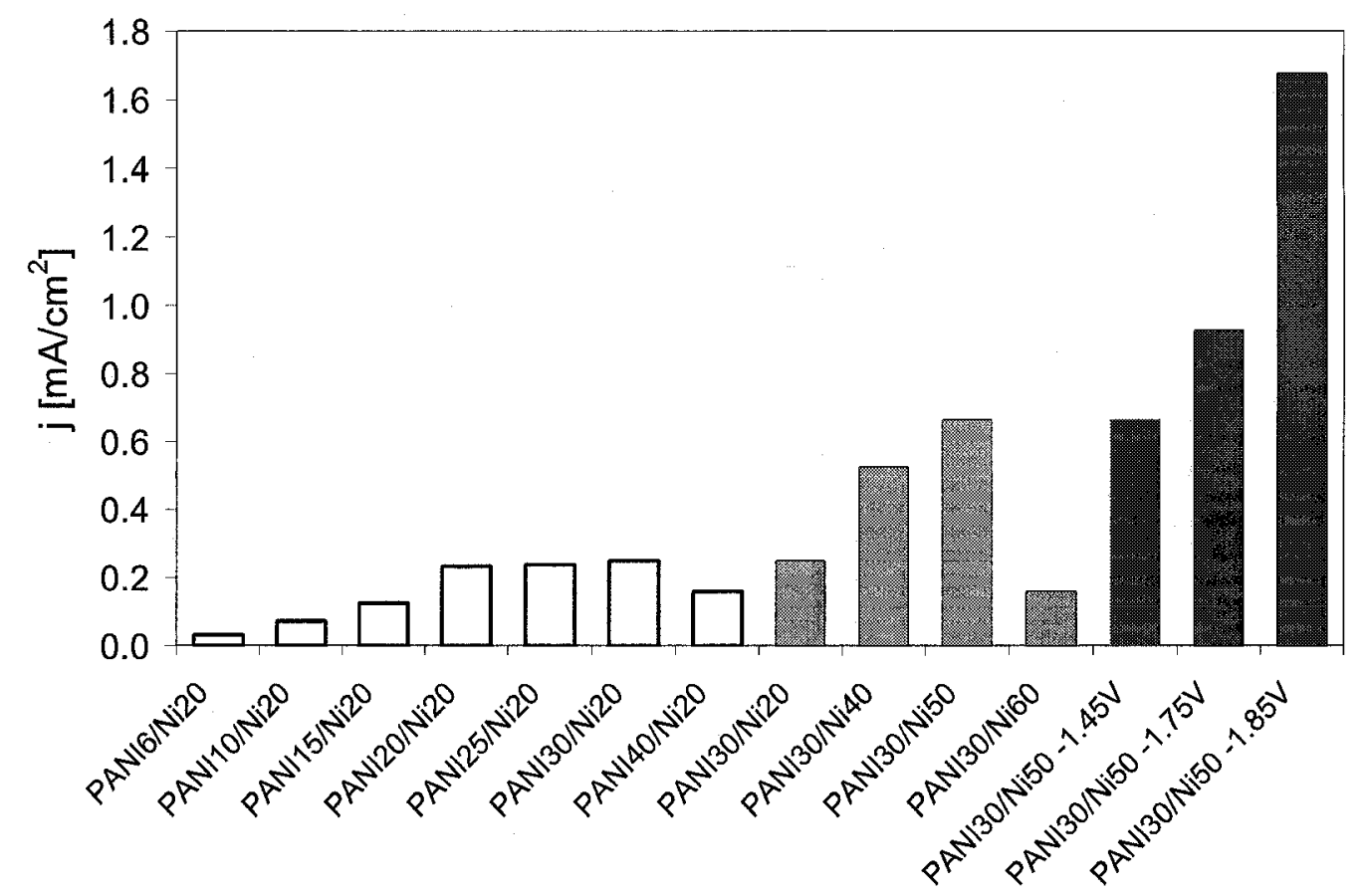

Figure 5.13 Figure 6: HER electrocatalytic activity of PANI/Ni electrocatalysts measured at $-0.35 \mathrm{~V}$. The white bars show the influence of PANI electrodeposition time, while the grey bars show the influence of $\mathrm{Ni}$ electrodeposition time. In both cases $\mathrm{Ni}$ was electrodeposited at $-1.45 \mathrm{~V}$. The black bars show the influence of $\mathrm{Ni}$ electrodeposition potential.

Both dependences in Fig. 5.13 (white and grey bars) yield a common "volcano-type" behaviour (i.e. a maximum), which is quite common in the area of electrocatalysts development $[21,71]$. In conclusion, PANI30/Ni50$1.85 \mathrm{~V}$ electrocatalyst shows the highest electrocatalytic activity in the HER, and will further be compared to the control (Ni plate), Ni-RVC, and Ni-nanoparticle electrocatalysts. 


\subsubsection{Relative comparison of PANI/Ni, Ni-RVC and Ni- nanoparticle electrocatalysts}

Ni-nanoparticles supported on Vulcan carbon (Fig. 5.6) offer a way of increasing the HER activity. This approach is commonly employed in PEM hydrogen and direct methanol fuel cells to fabricate membrane electrode assemblies using Pt-based carbon-supported electrocatalysts. Similarly, Ni-nanoparticles supported on Vulcan carbon (Fig. 5.6) could also be used as cathodes in PEM-type hydrogen generators and in regenerative alkaline fuel cells. For the latter application, Ni-coated RVC is also an interesting alternative since it offers high porosity and large surface area (Fig. 5.5).

Tafel curves recorded on the three types of $\mathrm{Ni}$-based electrocatalyst layers are plotted on the same graph (Fig. 5.14) in order to compare their relative electrocatalytic activity. The Tafel curve of the control surface (2D Ni plate) is also presented on the same plot for comparison. 


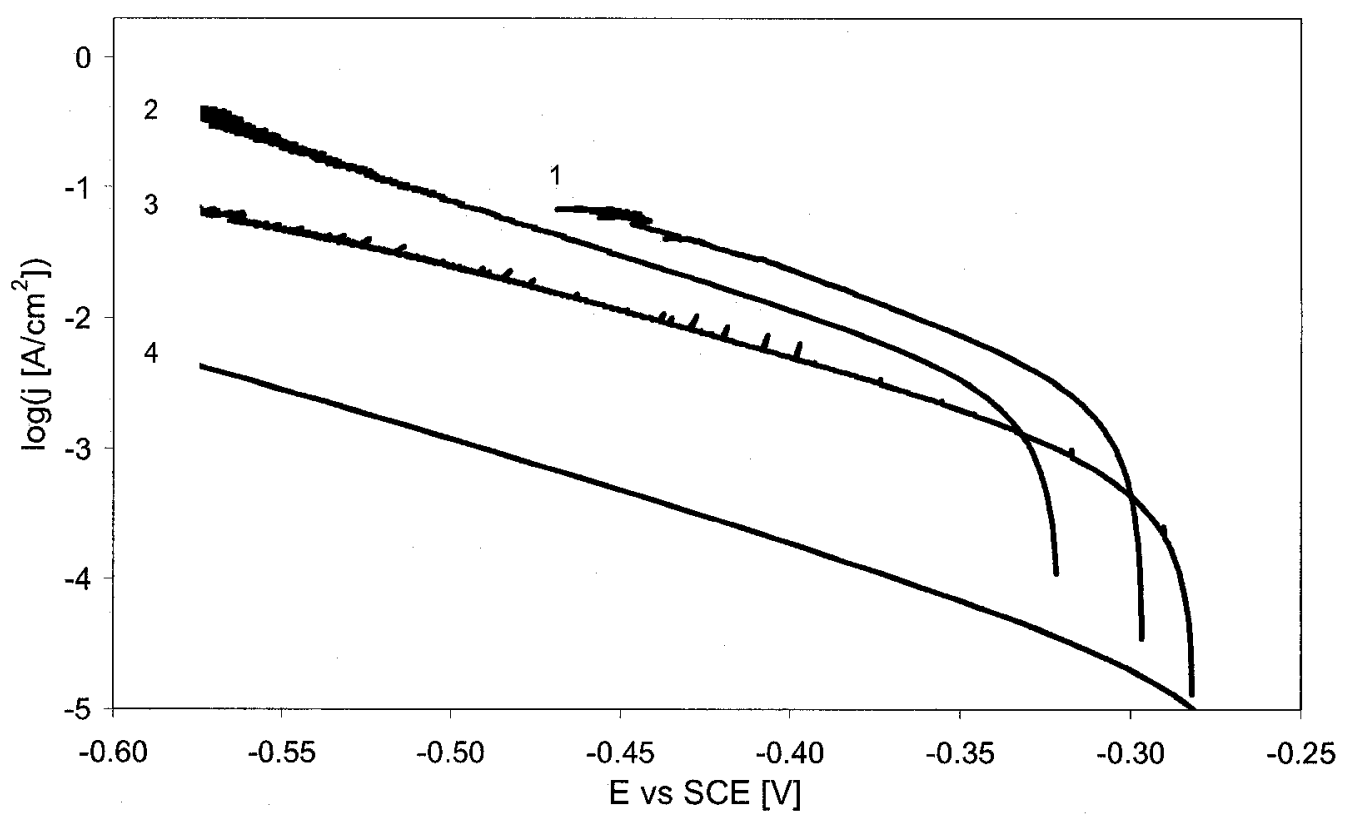

Figure 5.14 Linear polarization curves recorded on: (1) Ni-RVC, (2) PANI30/Ni50-1.85V, (3) Ni-nanoparticles and (4) the control Ni-plate surface. Scan rate $=0.5 \mathrm{mV} \mathrm{s}^{-1}$. The curves were corrected for the IRdrop.

All the curves show a classical Tafelian behavior which clearly demonstrates that the HER on all the electrocatalysts is a purely kinetically controlled reaction. The small deviation from linearity shown by the Ninanoparticle electrocatalyst at higher overpotentials (negative of $-0.5 \mathrm{~V}$ ) can be explained by the fact that some of the hydrogen bubbles produced at a high rate at these high overpotentials remain trapped inside the dense $\mathrm{Ni} / \mathrm{C}$ layer and under the Nafion membrane, physically blocking the electrocatalyst surface available for the HER, thus lowering the rate of hydrogen production (i.e. current density). 
The HER kinetic data obtained from the results in Fig. 5.14 are presented in Table 5.1.

Table 5.1 HER kinetic parameters obtained by analysis of the curves presented in Fig. 5.14.

\begin{tabular}{lccc}
\hline Electrocatalyst & $b\left[\mathrm{mV} \mathrm{decade}^{-1}\right]$ & $j_{o}\left[\mu \mathrm{A} \mathrm{cm}^{-2}\right]$ & $j\left[\mu \mathrm{Acm}^{-2}\right]$ at $-0.35 \mathrm{~V}$ \\
\hline Control surface & 117 & 6 & 34 \\
Ni-nanoparticles & 135 & 322 & 986 \\
PANI30/Ni50-1.85V & 114 & 1138 & 1680 \\
Ni-RVC & 107 & 1208 & 3678 \\
\hline
\end{tabular}

All the Tafel curves yield a similar Tafel slopes value, which confirms that the HER mechanism is the same on all the electrocatalysts, and is controlled by the adsorption of hydrogen on $\mathrm{Ni}$ to form a $\mathrm{Ni}-\mathrm{H}_{\text {ads }}$ bond $(\mathrm{Eq}$. 2.5). Further, the exchange current density $\left(j_{0}\right)$ values presented in the table demonstrate a superior apparent electrocatalytic activity of the three 3D Ni-based electrocatalyst layers at the equilibrium HER potential (zero overpotential), relative to the $2 \mathrm{D}$ control surface. However, although the exchange current density is frequently used to characterize electrocatalytic activity of an electrocatalyst, it is more appropriate to evaluate a catalytic activity at some fixed overpotential that is relevant to the actual operation of the hydrogen generator. Thus, the corresponding results at overpotential of $-0.35 \mathrm{~V}$ are also presented in Table 5.1. The electrocatalytic activity trend evaluated at the fixed overpotential is similar to the trend observed at equilibrium conditions. Thus, it can be observed that the amount of hydrogen produced using Ni nanoparticles is ca. 30 
times higher than if the control surface is used, while Ni-RVC and PANI30/Ni50-1.85V yield a 108 and 50 times higher electrocatalytic activity, respectively. However, it should be noted that Ni-RVC current density values were calculated with respect to the 3D surface area of a porous RVC cubicle substrate of volume $1 \mathrm{~cm}^{3}$ (see Fig. 4.2) while current density values on the other surfaces were calculated with respect to the projected $2 \mathrm{D}$ area of the glassy carbon substrate surface $\left(0.27 \mathrm{~cm}^{2}\right)$ - see Fig. 4.1. Therefore, it is not quite possible to compare the electrocatalytic activity of Ni-RVC to the other three electrocatalysts. Further, Fig. 5.14 and Table 5.1 show that the electrocatalytic activity of the Ni-nanoparticles is lower than that of PANI30/Ni50-1.85V, which is a surprise since the Ni nanoparticle size ratio between the two electrocatalysts is ca. 85 , and the corresponding thickness of the two layers is similar. However, the comparison of the two micrographs in Fig. 5.4b and Fig. 5.6 show that $\mathrm{Ni}$ nanoparticles are mostly agglomerated on the carbon surface, which limits the available active surface area for the HER. In addition, the corresponding $\mathrm{Ni}$ nanoparticle loading, i.e. density of $\mathrm{Ni}$ nanoparticles on the carbon support, is low. A decrease in the particle size, an increase in their loading, and minimization of their agglomeration would further increase the electrocatalytic activity of the electrocatalyst, which is the work proposed for future experiments in our laboratory. Nevertheless, we have clearly demonstrated that it is possible to produce Ni nanoparticles anchored on a carbon support, and then use them to produce hydrogen by 
water electrolysis in an acidic medium. To the best of our knowledge, this is the first such demonstration published in literature.

In conclusion, the information obtained from the Tafel polarization data in Fig. 5.14 shows that all the Ni-based 3D electrocatalyst layers are more active in the HER than the 2D control surface, which is due to an increase in the number of HER active sites, i.e. a surface area increase.

\subsection{Electrochemical impedance spectroscopy (EIS) measurements}

SEM, TEM, and $d c$ Tafel polarization techniques gave the information on the morphology and overall electrocatalytic activity of the electrocatalyst layers studied. However, these techniques cannot provide information on the structure of the electrode/electrolyte interface in terms of the surface charge distribution, double-layer capacitance, and hydrogen adsorption. Therefore, electrochemical impedance spectroscopy (EIS) was utilized to further investigate the electrode/electrolyte interface and the corresponding processes that occur at the electrode surface. EIS measurements were carried out at selected overpotentials in the HER potential range.

Fig. 5.15 shows an example of EIS spectra recorded on PANI30/Ni50-1.85 at several selected overpotentials. It can be observed from the presented Nyquist plot that all the spectra display a semicircular trend. 


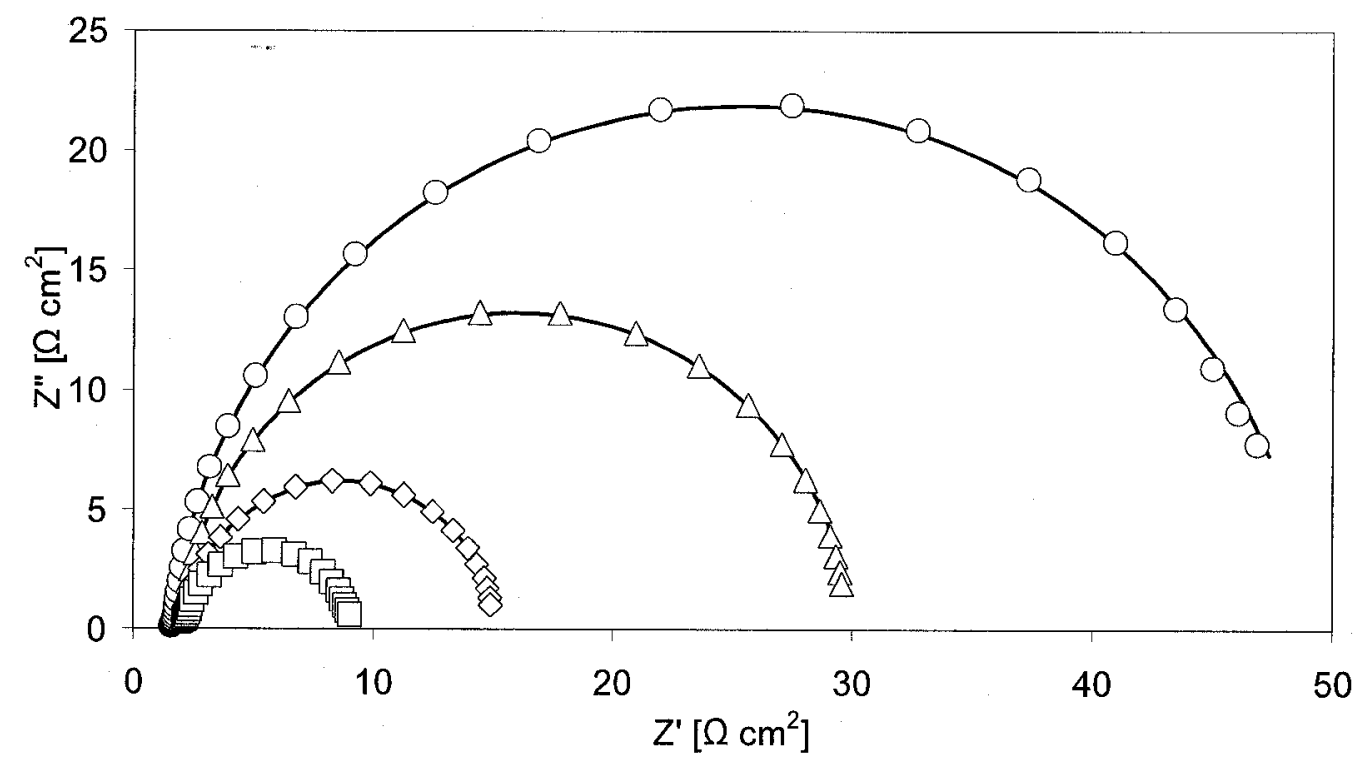

Figure 5.15 Nyquist plot showing the EIS response of PANI30/Ni50-1.85V electrocatalyst at various overpotentials in the HER region. Symbols are experimental and solid lines are modeled data. $(\mathrm{O})-0.37 \mathrm{~V},(\Delta)-0.42 \mathrm{~V}$, $(\diamond)-0.47 \mathrm{~V}$, and $(\square)-0.52 \mathrm{~V}$.

With an increase in overpotential the diameter of the semicircle decreases, which is due to a decrease in the HER resistance and thus, through the Ohm law, an increase in the HER current. This is quite consistent with the corresponding $d c$ behavior (Fig. 5.14, curve 2). The plot shows that the semicircles are not distorted, which indicates that the recorded EIS behavior represents a response of a process characterized by only one time constant. Therefore, in order to obtain the physical picture of the electrode/electrolyte interface and the processes occurring at the electrode surface, experimental EIS data were modeled using a non-linear least-square fit method. For modeling of EIS spectra on PANI/Ni 
electrocatalysts, a one-time-constant equivalent electrical circuit (EEC) was used (Fig. 5.16a), where $\mathrm{CPE}_{1}$ represents the double-layer capacitance $\left(\Omega^{-1} \mathrm{~s}^{\mathrm{n}} \mathrm{cm}^{-2}\right)$, and $\mathrm{R}_{1}$ represents the charge-transfer resistance $\left(\Omega \mathrm{cm}^{2}\right)$ associated with the HER.

(a)

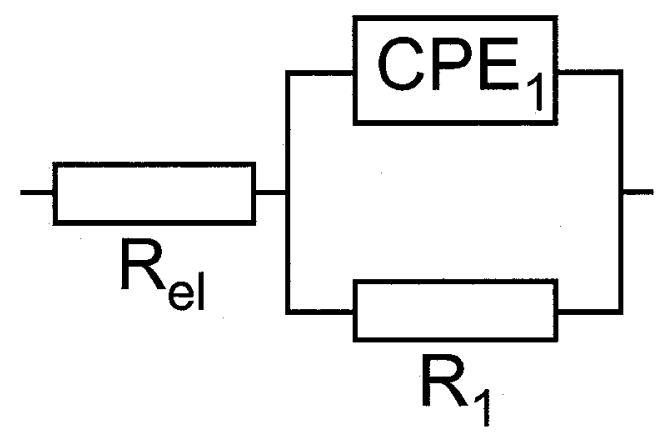

(b)

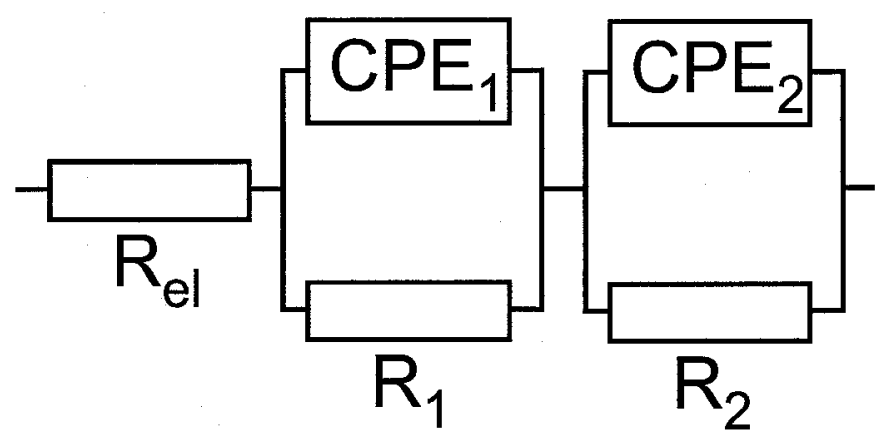

Figure 5.16 EEC models used to fit the EIS response of the investigated electrocatalysts in the HER: (a) one-time constant, and (b) two-time constant serial model. $\mathrm{R}=$ resistance, $\mathrm{CPE}=$ constant phase element.

The fitting procedure showed that a better agreement between theoretical and experimental data was obtained when pure capacitance was replaced by a frequency-dependent constant-phase element, CPE. The use of a $\mathrm{CPE}$ was required due to the distribution of the relaxation times as a result of inhomogeneities present at the micro- or nano-levels, such as surface roughness/porosity, adsorption, or diffusion [23]. Fig. 5.15 shows that an excellent agreement between the experimental data (symbols) and the 
modeled data was obtained, thus justifying the use of the proposed onetime constant EEC (Fig. 5.16a). Experimental EIS data obtained on the control surface (2D Ni plate) were also fit to a one-time constant EEC and, in this case also, an excellent agreement between the experimental and modeled data was obtained (see Fig. A.1 in Appendix A). In both cases, the value of $\mathrm{CPE}_{1}$ remained constant with overpotential $\left(12 \pm 1 \times 10^{-4} \Omega^{-1} \mathrm{~s}^{\mathrm{n}} \mathrm{cm}^{-2}\right.$ for PANI30/Ni50-1.85V, and $33 \pm 4 \times 10^{-6} \Omega^{-1} \mathrm{~s}^{\mathrm{n}} \mathrm{cm}^{-2}$ for the control surface), confirming that $\mathrm{CPE}_{1}$ indeed represents the double-layer capacitance. In contrast, the value of $R_{1}$ decreased with overpotential, confirming that $R_{1}$ represents the response of chargetransfer resistance, related to the HER kinetics (see Table A.1 in Appendix A).

On the other hand, modeling of EIS spectra obtained on Ni-RVC and Ni-nanoparticles using a one-time constant EEC, resulted in a large error. However, when a two-time-constant EEC was used, (Fig. 5.16b), the agreement between the model and experimental data was excellent. Fig. 5.17 shows examples of experimental (symbols) and modeled (lines) data in the form of a Nyquist plot for the Ni-RVC (Fig. 5.17a) and Ninaoparticles (Fig. 5.17) electrocatalysts. 

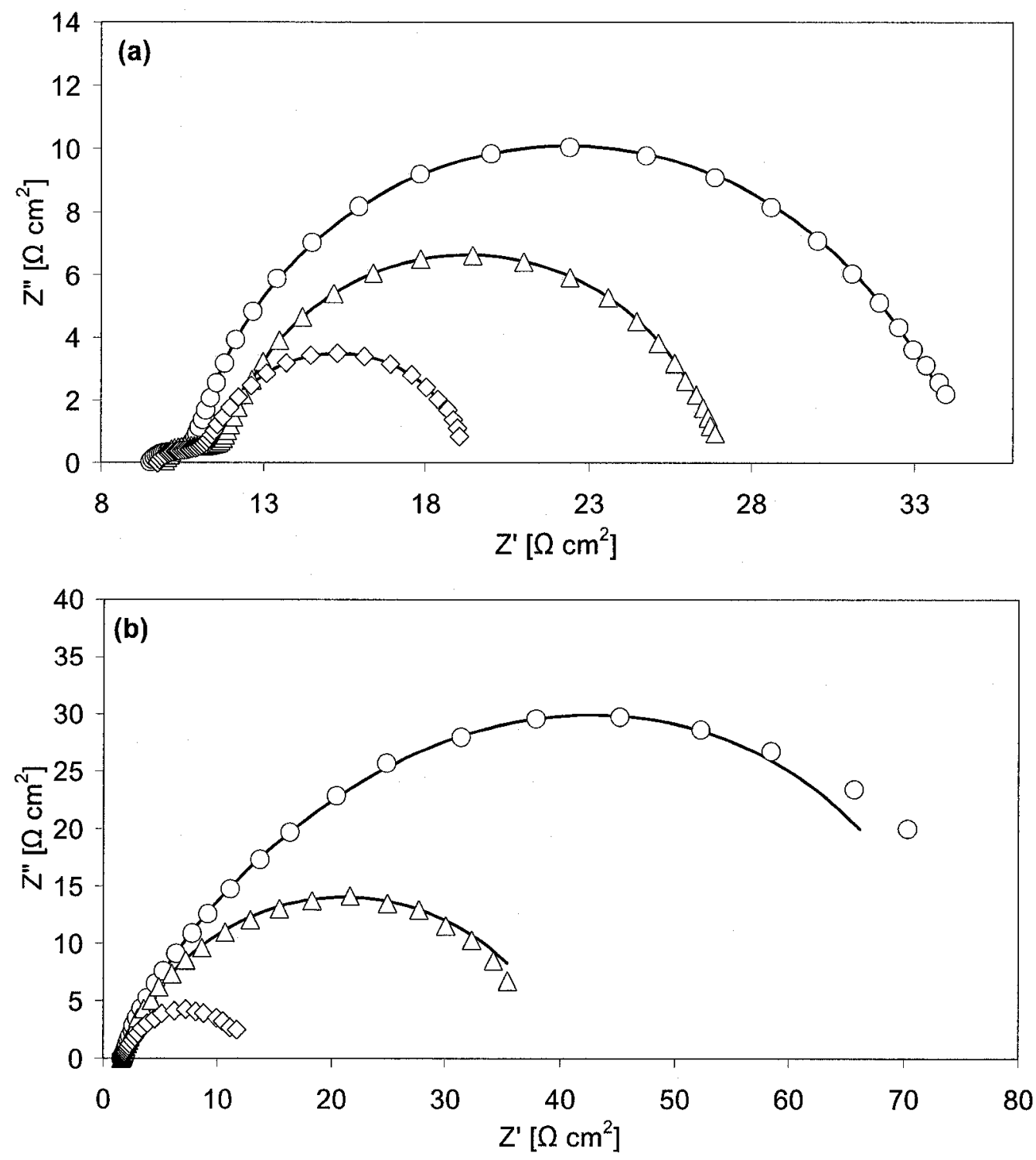

Figure 5.17 Nyquist plots showing the EIS response of (a) Ni-RVC, and (b) Ni-nanoparticle electrocatalysts at various overpotentials in the HER region. Symbols are experimental and solid lines are modeled data. (O) $-0.35 \mathrm{~V},(\Delta)-0.40 \mathrm{~V}$, and $(\diamond)-0.48 \mathrm{~V}$.

It is also visually obvious from these two figures that there are two time constants that characterize the EIS behaviour of the two electrocatalysts. 
Namely, the EIS plot of Ni-RVC shows these two time constants quite distinctively, as two well-resolved semicircles; the larger in the lower frequency region, and the smaller in the high frequency region. On the other hand, the corresponding two semicircles on the EIS plot of $\mathrm{Ni}$ nanoparticles are not well-resolved. However, a careful visual inspection of the spectrum recorded at the lowest HER overpotential (circles) also reveals the presence of two overlapping semicircles.

In order to prescribe the two time constants recorded on Ni-RVC and Ni-nanoparticle electrocatalysts to specific physical properties, we should first examine their overpotential behavior. The inspection of the fitted EIS data showed that the overpotential behavior of the first time constant $\left(\tau_{1}=\mathrm{CPE}_{1} \times \mathrm{R}_{1}\right)$ is potential independent (Ni-RVC: $\tau_{1}=15 \pm 3 \times 10^{-5} \mathrm{~s}$, Ninanoparticles: $\tau_{1}=0.2 \pm 0.2 \mathrm{~s}$ ), indicating that the time constant is, in this case, related to the electrode surface porosity response $[40,70]$. The twotime constant EEC has been used in literature to describe a response of the HER on porous electrodes $[33,45,69]$. The second time constant $\left(\tau_{2}=\mathrm{CPE}_{2} \times \mathrm{R}_{2}\right.$ ) decreased with increasing HER overpotential (i.e. $R_{2}$ decreased, Table A.2, and $\mathrm{CPE}_{2}$ remained relatively constant, Ni-RVC: $\mathrm{CPE}_{2}=4.8 \pm 0.3 \times 10^{-2} \quad \Omega^{-1} \mathrm{~s}^{\mathrm{n}} \mathrm{cm}^{-2}, \quad$ Ni-nanoparticles: $\mathrm{CPE}_{2}=6 \pm 4 \times 10^{-2} \Omega^{-1} \mathrm{~s}^{\mathrm{n}} \mathrm{cm}^{-2}$ ), which indicates that this time constant is related to the HER electron-transfer kinetics $\left(R_{2}\right)$ and double-layer capacitance $\left(\mathrm{CPE}_{2}\right)$. The absence of the hydrogen adsorption time constant on all surfaces is in agreement with the $d c$ measurements (Figs. 
$5.7-5.9$, and 5.14), which demonstrated that the Volmer step (Eq. 2.5) is the rate determining step in the HER. If the Heyrovsky or Tafel step (Eqs. 2.6 and 2.7 , respectively) were the rate determining step (desorption of hydrogen from the $\mathrm{Ni}$ surface) then EIS would detect this as the appearance of the adsorption time constant, which would replace $\tau_{1}$ in the current model. This (adsorption) time constant would be characterized by a decrease in adsorption resistance $\left(R_{a d s}\right)$ and an increase in adsorption capacitance ( $\left.\mathrm{CPE}_{\mathrm{ads}}\right)$ with overpotential in such a way that the resulting time constant decreases with overpotential.

Fig. 5.18 compares the relative electrocatalytic activity of the four investigated electrocatalysts. The data was obtained by normalizing the HER charge transfer resistance of the three 3D electrocatalysts, measured in the potential region relevant to the actual generator operation (from -0.35 to $-0.40 \mathrm{~V}$ ), to that of the $2 \mathrm{D}$ control electrocatalyst (which thus has the relative activity of one). 


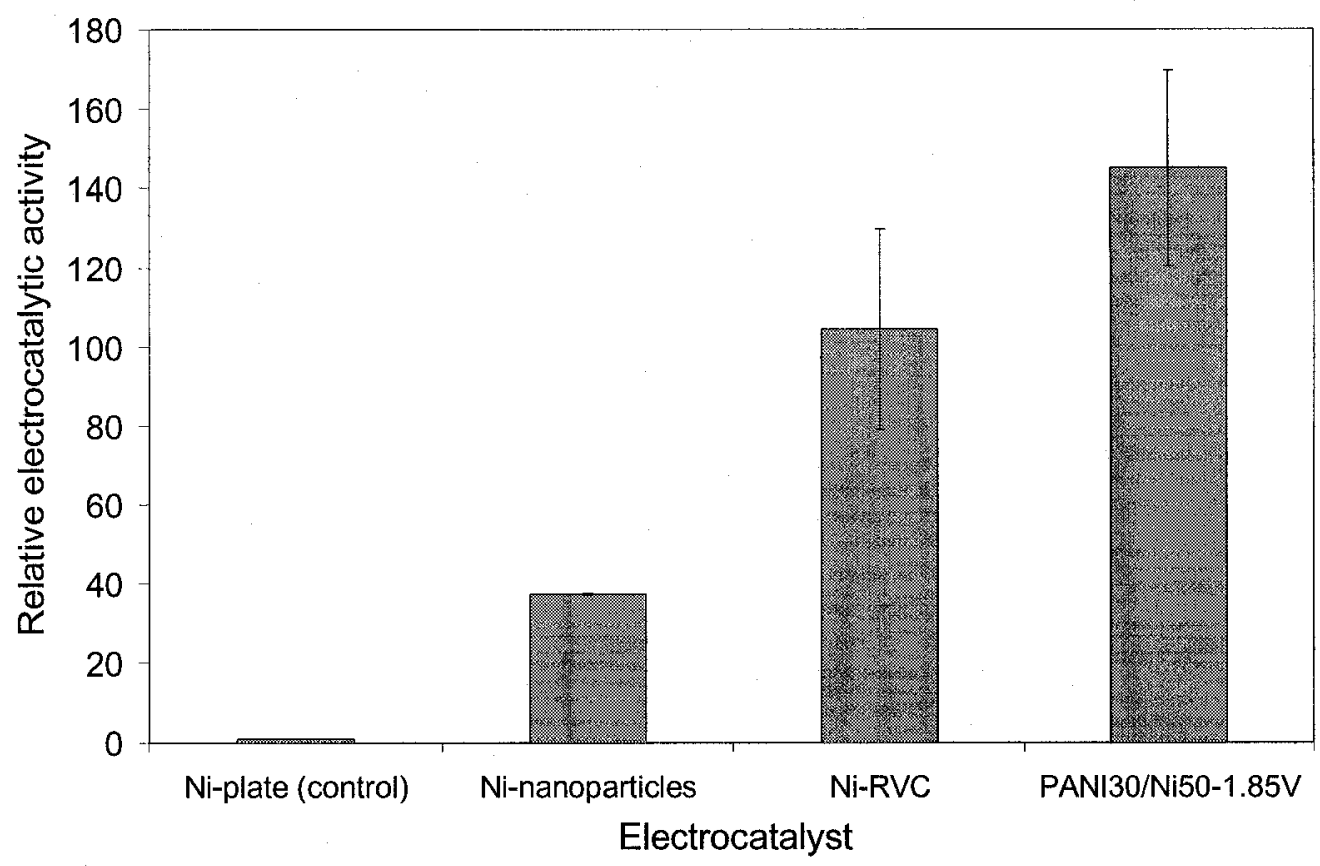

Figure 5.18 Relative electrocatalytic activity of the investigated electrocatalysts in the HER. The data were calculated from charge transfer resistance values obtained from EIS measurements performed in the potential region relevant to the operation of a hydrogen generator $(-0.35 \mathrm{~V}$ to $-0.40 \mathrm{~V}$ ).

The results demonstrate that PANI30/Ni50-1.85V electrocatalyst is ca. 150 times more active in hydrogen production that the control electrocatalyst, followed by Ni-RVC, which is almost 110 times more active, and then $\mathrm{Ni}$ nanoparticles that yield a 35 times higher HER relative activity. Contrary to the trend observed with the $d c$ measurements presented in Fig. 5.14 and Table 5.1, the highest relative activity is obtained with the PANI30/Ni50-1.85V electrocatalysts. This difference is due to the difference in performing $d c$ Tafel and ac EIS measurements. Namely, the latter measurements were done at a constant potential for a prolonged length of time (20 minutes at a constant potential), during which 
a significant amount of gaseous hydrogen was produced, which is not the case in relatively faster $d c$ measurements. It appears that the hydrogen produced during the EIS measurement remained trapped inside the porous Ni-RVC structure, blocking the pores (Fig. 5.5) and thus access of the electrolyte to the interior of the electrocatalyst. This effectively reduced the surface area of the electrocatalyst, resulting in a lower amount of hydrogen produced. Nevertheless, the EIS results in Fig. 5.18 clearly demonstrate that all the Ni-based $3 \mathrm{D}$ electrocatalyst layers are more active in the HER than the 2D control electrocatalyst, which is due to an increased electrochemically active surface area of nickel. 


\section{CHAPTER 6}

\section{CONCLUSION}

- It was shown that patterning of a GC electrode substrate surface with a three-dimensional PANI matrix is a convenient way of increasing the surface area of electrodeposited nickel, and thus its apparent electrocatalytic activity in the hydrogen evolution reaction.

- The influence of PANI and Ni loading (i.e. electrodeposition time) and the $\mathrm{Ni}$ electrodeposition potential on the apparent electrocatalytic activity of the produced electrocatalyst layers was investigated.

- The morphology of formed 3D PANI/Ni layers was characterized by spherical/globular particles of an average diameter ranging from 2.3 to 4.6 $\mu \mathrm{m}$, depending on the $\mathrm{Ni}$ electrodeposition potential. These $\mathrm{Ni}$ layers were of a poly-crystalline structure, showing a small degree of amorphousness.

- It was demonstrated that all the investigated PANI/Ni layers offer a higher electrocatalytic activity in the HER than the quazi twodeimenzional control surface (Ni plate). The most electrocatalytically active layer was obtained when PANI was electrodeposited for 30 min 
and $\mathrm{Ni}$ was electrodeposited for $50 \mathrm{~min}$ at $-1.85 \mathrm{~V}$ (PANI30/Ni50-1.85V electrocatalyst).

- It was also demonstrated that it is possible to produce a Ni-based HER electrocatalyst layer by synthesizing $\mathrm{Ni}$ nanoparticles and supporting them on Vulcan carbon. An average Ni nanoparticle size obtained was $27 \mathrm{~nm}$, and the nanoparticles were of a single-crystalline structure characterized by the (200) orientation. This electrocatalyst layer also offered a significantly higher electrocatalytic activity in the HER then the control surface, but lower then that of PANI30/Ni50-1.85V.

- Finally, the electrocatalytic activity of the PANI30/Ni50-1.85V electrocatalyst was compared to the activity of a 3D catalyst produced by coating a porous RVC cube substrate with $\mathrm{Ni}$. This electrocatalyst showed the highest HER electrocatalytic activity among the investigated layers when tested under potentiodynamic polarization conditions. However, under the potentiostatic conditions, PANI30/Ni50$1.85 \mathrm{~V}$ showed a significantly higher electrocatalytic activity.

- $D c$ and ac measurements revealed that the Volmer step, which involves the adsorption of hydrogen to form a $\mathrm{Ni}-\mathrm{H}_{\text {ads }}$ bond, is the rate determining step in the HER on all the electrocatalysts investigated. 


\section{FUTURE WORK}

Further optimization of carbon-supported Ni-nanoparticles through reducing the particle size and preventing particle agglomeration is essential in order to increase their electrocatalytic activity in the HER. The possibility of producing carbon-supported Ni-nanoparticles allows for the design of cheaper membrane-electrode-assemblies for PEM-type hydrogen generators.

PANI/Ni electrocatalysts and Ni-coated RVC could be used as cathodes in regenerative alkaline fuel cells. A decrease in the size and an increase in the density of the $\mathrm{Ni}$ particles inside the PANI matrix is necessary to increase the electrocatalyst's surface area and hydrogen production rate. 


\section{REFERENCES}

1. Kruger, P., Int. J. Hydrogen Energy (2000). 25: p. 395.

2. Hijikata, T., Int. J. Hydrogen Energy (2002). 27: p. 115.

3. Dun, S., Int. J. Hydrogen Energy, (2002). 27: p. 235.

4. Mitsugi, C., A. Harumi, and F. Kenzo, Int. J. Hydrogen Energy (1998). 23: p. 159.

5. Nicholson, W., Account of the new electrical or galvanic apparatus of sig. Alex. Volta, and experiments performed with the same. Nicholson's J. Nat. Philos. Chem. Arts, (1800). 4: p. 179.

6. Kreuter, W. and H. Hofman, Int. J. Hydrogen Energy, (1998). 23: p. 661.

7. Ulleberg, O., Int. J. Hydrogen Energy, (2003). 28: p. 21.

8. Navarro-Flores, E. and S. Omanovic, J. Molecular Catalysis A: Chemical, (2005). 242: p. 182.

9. Kreuter, W. and H. Hofmann, Hydrogen Energy Progress XI, (1996). 1: p. 537.

10. Mori, H., et al., Hydrogen Energy Progress XI, (1996). 1: p. 579.

11. Inazumi, C., et al., Hydrogen Energy Progress XI, (1996). 1: p. 579.

12. Rasten, E., G. Hagen, and R. Tunold, Electrochimica Acta, (2003). 48: p. 3945.

13. Crockett, R.G.M., et al., Applied Energy, (1995). 51: p. 249.

14. Millet, P., R. Durand, and M. Pineri, Int. J. Hydrogen Energy, (1990). 15(4): p. 245.

15. Srinivasan, S., et al., in Proc. Space Electrochemical Research and Technology Conf. (1987): NASA Lewis Research Center, Cleveland.

16. Marshall, A., et al., Energy, (2007). 32: p. 431.

17. Han, S.D., et al., Indian Journal of Chemistry, (2002). 41: p. 245.

18. Millet, P., F. Andolfatto, and R. Durand, Int. J. Hydrogen Energy, (1996). 21(2): p. 87. 
19. Chen, L. and A. Lasia, J. Electrochemical Society, (1991). 138: p. 3321.

20. Shervedani, R.K. and A. Lasia, J. Electrochemical Society, (1997). 144: p. 2652.

21. Group, S.E., in Instrumental Methods in Electrochemistry. (1985), Wiley: New York.

22. Trasatti, S., J. Electroanalytical Chemistry (1972) 39: p. 163.

23. Navarro-Flores, E., Z. Chong, and S. Omanovic, J. Molecular Catalysis A: Chemical, (2005). 226: p. 179.

24. Conway, B.E. and G. Jerkiewicz, Electrochimica Acta, (2000). 45: p. 4075.

25. Hitz, C. and A. Lasia, J. Electroanalytical Chemistry, (2001). 500: p. 213.

26. Los, P., A. Rami, and A. Lasia, J. Applied Electrochemistry, (1993) 23: p. 135 .

27. Ezaki, H., M. Morinaga, and S. Watanabe, Electrochimica Acta, (1993). 38: p. 557.

28. Ezaki, H., et al., Electrochimica Acta, (1994). 39: p. 1769.

29. Highfield, J.G., E. Claude, and K. Oguro, Electrochimica Acta, (1999). 44: p. 2805.

30. Metikos-Hukovic, M. and A. Jukic, Electrochimica Acta, (2000). 45: p. 4159.

31. Shibutani, H., et al., Electrochimica Acta, (1998). 43: p. 3235.

32. Ezaki, H., et al., Int. J. Hydrogen Energy, (1996). 21: p. 877.

33. Losiewicz, B., et al., Int. J. Hydrogen Energy, (2004). 29: p. 145.

34. Shervedani, R.K. and A. Lasia, J. Applied Electrochemistry, (1999). 29: p. 979.

35. Simpraga, R., et al., J. Electroanalytical Chemistry, (1997). 424: p. 141.

36. Tanaka, S., N. Hirose, and T. Tanaki, Int. J. Hydrogen Energy (2000). 25: p. 481. 
37. Jaksic, M.M., Electrochimica Acta, (2000). 45: p. 4085.

38. Jaksic, M.M., Solid State lonics, (2000). 136-137: p. 733.

39. Dabo, P., et al., J. Applied Electrochemistry, (1998). 28: p. 601.

40. Hu, W., Int. J. Hydrogen Energy (2000). 25: p. 111.

41. Miles, M.H. and M.A. Thomason, J. Electrochemical Society, (1976). 123: p. 1459.

42. Conway, B.E. and J.O.M. Bockris, J. Chemical Physics (1957) 26: p. 532 .

43. Krishtalik, L.I. Advances in Electrochemistry and Electrochemical Engineering, ed. P. Delahay and C. Tobias. (1970), New York: Interscience.

44. Trasatti, S., J. Chemical Society, Faraday Transactions (1972). 68: p. 229.

45. Birry, L. and A. Lasia, J. Applied Electrochemistry, (2004). 34: p. 735.

46. Kondoh, M., et al., J. New Materials for Electrochemical Systems, (2000). 3: p. 61.

47. Wang, X., I.M. Hsing, and P.L. Yue, J. Power Sources, (2001). 96: p. 282.

48. InfoMine - Mining Intelligence and Technology. [cited; Available from: http://www.infomine.com/investment/metalprices/.

49. Lasia, A., J. Electroanalytical Chemistry, (1998). 454: p. 115.

50. Brown, I.J. and S. Sotiropoulos, J. Applied Electrochemistry, (2000). 30: p. 107.

51. Sarrazin, J., M. Persin, and M. Cretin, Macromolecular Symposia, (2002). 188: p. 1.

52. Saxena, V. and B.D. Malhotra, Current Applied Physics, (2003). 3: p. 293.

53. Chialvo, M.R.G.d. and A.C. Chialvo, J. Electroanalytical Chemistry, (1998). 448: p. 87. 
54. Bensebaa, F., et al., J. Physical Chemistry B, (2005). 109: p. 15339.

55. Bock, C., et al., J. American Chemical Society, (2004). 126: p. 8028.

56. Ralph, T.R. and M.P. Hogarth, Platinum Metals Review, (2002). 46: p. 117.

57. Wasmus, S. and A. Küver, J. Electroanalytical Chemistry, (1999). 461: p. 14.

58. Zeng, J., J.Y. Lee, and W. Zhou, J. Power Sources, (2006). 159: p. 509.

59. Zhang, X., et al., Materials Research Bulletin, (2007). 42: p. 327.

60. Boudjahem, A., et al., Langmuir, (2004). 20: p. 208.

61. Chen, D. and C. Hsieh, J. Materials Chemistry, (2002). 12: p. 2412.

62. Chen, D. and S. Wu, Chemistry of Materials, (2000). 12: p. 1354.

63. Hou, Y. and S. Gao, J. Materials Chemistry, (2003). 13: p. 1510.

64. Jung, K.Y., et al., Materials Science and Engineering B, (2007). 137: p. 10.

65. Ni, X.-M., et al., J. Crystal Growth, (2003). 252: p. 612.

66. Singla, M.L., et al., Catalytic Behavior of Nickel Nanoparticles Stabilized By Lower Alkyl Ammonium Bromide in Aqueous Medium. Applied Catalysis A: General, (2007). 323: p. 51.

67. Wojcieszak, R., et al., J. Colloid and Interface Science, (2006). 299: p. 238.

68. Zhang, D.E., et al., Materials Letters, (2005). 59: p. 2011.

69. Borresen, B., G. Hagen, and R. Tunold, Electrochimica Acta, (2002). 47: p. 1819.

70. Ndzebet, E. and O. Savadogo, Int. J. Hydrogen Energy, (1995). 20: p. 635.

71. Damian, A., K. Maloo, and S. Omanovic, Chem. Biochem. Eng. Q., (2007). 21: p. 21. 


\section{APPENDIX A}

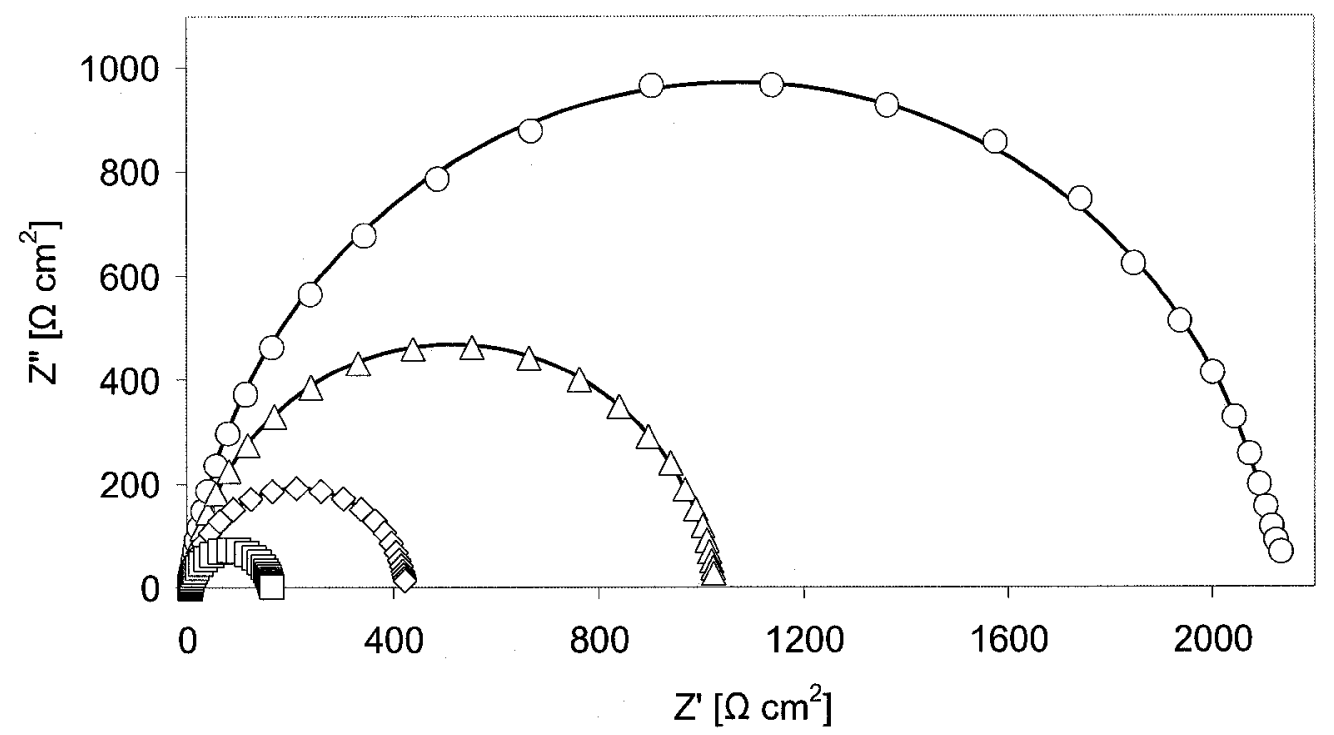

Figure A.1 Nyquist plot showing the EIS response of control Ni-plate surface at various overpotentials in the HER region. Symbols are experimental and solid lines are modeled data. (O) $-0.37 \mathrm{~V},(\Delta)-0.42 \mathrm{~V}$, $(\diamond)-0.47 \mathrm{~V}$, and $(\square)-0.52 \mathrm{~V}$.

Table A.1 EEC parameters obtained by fitting EIS experimental spectra recorded at various overpotentials on the control $\mathrm{Ni}$ plate and PANI30/Ni50 -1.85 V electrocatalyst.

\begin{tabular}{ccccccc}
\hline$E[V]$ & $R_{\text {el }}[\Omega]$ & $\begin{array}{c}\mathrm{CPE}_{1} \\
{\left[\mathrm{~F} \mathrm{~cm}^{-2}\right]}\end{array}$ & $\mathrm{n}_{1}$ & $\begin{array}{c}\mathrm{R}_{1} \\
{\left[\Omega \mathrm{cm}^{2}\right]}\end{array}$ & $\mathrm{C}_{\mathrm{dl}}\left[\mathrm{F} \mathrm{cm}{ }^{-2}\right]$ & $\tau[\mathrm{s}]$ \\
\hline $\begin{array}{c}\text { Control Ni plate } \\
-0.27\end{array}$ & 7.14 & $4.59 \mathrm{E}-05$ & 0.92 & 5354 & $2.28 \mathrm{E}-05$ & $1.2 \mathrm{E}-01$ \\
-0.28 & 7.14 & $4.34 \mathrm{E}-05$ & 0.93 & 5508 & $2.24 \mathrm{E}-05$ & $1.2 \mathrm{E}-01$ \\
-0.29 & 7.15 & $4.16 \mathrm{E}-05$ & 0.93 & 5208 & $2.20 \mathrm{E}-05$ & $1.1 \mathrm{E}-01$ \\
-0.3 & 7.15 & $4.00 \mathrm{E}-05$ & 0.93 & 4836 & $2.17 \mathrm{E}-05$ & $1.0 \mathrm{E}-01$ \\
-0.31 & 7.16 & $3.86 \mathrm{E}-05$ & 0.93 & 4398 & $2.13 \mathrm{E}-05$ & $9.4 \mathrm{E}-02$ \\
-0.32 & 7.16 & $3.77 \mathrm{E}-05$ & 0.93 & 3977 & $2.09 \mathrm{E}-05$ & $8.3 \mathrm{E}-02$ \\
-0.33 & 7.17 & $3.65 \mathrm{E}-05$ & 0.94 & 3532 & $2.07 \mathrm{E}-05$ & $7.3 \mathrm{E}-02$ \\
-0.34 & 7.18 & $3.57 \mathrm{E}-05$ & 0.94 & 3127 & $2.05 \mathrm{E}-05$ & $6.4 \mathrm{E}-02$ \\
-0.35 & 7.21 & $3.49 \mathrm{E}-05$ & 0.94 & 2762 & $2.04 \mathrm{E}-05$ & $5.6 \mathrm{E}-02$ \\
-0.36 & 7.22 & $3.42 \mathrm{E}-05$ & 0.94 & 2432 & $2.04 \mathrm{E}-05$ & $5.0 \mathrm{E}-02$ \\
-0.37 & 7.25 & $3.37 \mathrm{E}-05$ & 0.94 & 2118 & $2.03 \mathrm{E}-05$ & $4.3 \mathrm{E}-02$ \\
-0.38 & 7.29 & $3.33 \mathrm{E}-05$ & 0.95 & 1848 & $2.03 \mathrm{E}-05$ & $3.8 \mathrm{E}-02$ \\
-0.39 & 7.34 & $3.29 \mathrm{E}-05$ & 0.95 & 1601 & $2.04 \mathrm{E}-05$ & $3.3 \mathrm{E}-02$ \\
-0.4 & 7.37 & $3.27 \mathrm{E}-05$ & 0.95 & 1378 & $2.04 \mathrm{E}-05$ & $2.8 \mathrm{E}-02$ \\
-0.41 & 7.37 & $3.24 \mathrm{E}-05$ & 0.95 & 1186 & $2.04 \mathrm{E}-05$ & $2.4 \mathrm{E}-02$ \\
-0.42 & 7.33 & $3.22 \mathrm{E}-05$ & 0.95 & 1015 & $2.05 \mathrm{E}-05$ & $2.1 \mathrm{E}-02$ \\
-0.43 & 7.33 & $3.18 \mathrm{E}-05$ & 0.95 & 868 & $2.05 \mathrm{E}-05$ & $1.8 \mathrm{E}-02$ \\
-0.44 & 7.39 & $3.14 \mathrm{E}-05$ & 0.95 & 727 & $2.04 \mathrm{E}-05$ & $1.5 \mathrm{E}-02$ \\
-0.45 & 7.40 & $3.15 \mathrm{E}-05$ & 0.95 & 608 & $2.05 \mathrm{E}-05$ & $1.2 \mathrm{E}-02$ \\
-0.46 & 7.28 & $3.13 \mathrm{E}-05$ & 0.95 & 501 & $2.06 \mathrm{E}-05$ & $1.0 \mathrm{E}-02$ \\
-0.47 & 7.26 & $3.13 \mathrm{E}-05$ & 0.95 & 416 & $2.07 \mathrm{E}-05$ & $8.6 \mathrm{E}-03$ \\
& & & & & &
\end{tabular}


Appendix

\begin{tabular}{|c|c|c|c|c|c|c|}
\hline-0.48 & 7.31 & 3.12E-05 & 0.96 & 343 & $2.08 \mathrm{E}-05$ & 7.1E-03 \\
\hline-0.49 & 7.39 & 3.11E-05 & 0.96 & 281 & 2.08E-05 & 5.9E-03 \\
\hline-0.5 & 7.44 & 3.11E-05 & 0.96 & 230 & 2.09E-05 & $4.8 E-03$ \\
\hline-0.52 & 7.53 & 3.12E-05 & 0.96 & 157 & 2.09E-05 & 3.3E-03 \\
\hline-0.54 & 7.55 & 3.11E-05 & 0.96 & 107 & 2.12E-05 & $2.3 E-03$ \\
\hline-0.56 & 7.72 & 3.12E-05 & 0.96 & 75 & 2.12E-05 & 1.6E-03 \\
\hline-0.58 & 7.66 & 3.11E-05 & 0.96 & 54 & 2.12E-05 & 1.1E-03 \\
\hline-0.6 & 7.78 & 3.09E-05 & 0.96 & 39 & 2.13E-05 & 8.3E-04 \\
\hline-0.62 & 7.79 & 3.09E-05 & 0.96 & 29 & 2.13E-05 & $6.1 \mathrm{E}-04$ \\
\hline-0.64 & 8.31 & 3.07E-05 & 0.96 & 22 & $2.10 \mathrm{E}-05$ & 4.6E-04 \\
\hline-0.66 & 8.13 & 2.99E-05 & 0.96 & 17 & 2.09E-05 & $3.5 \mathrm{E}-04$ \\
\hline-0.68 & 7.88 & 2.96E-05 & 0.96 & 13 & 2.08E-05 & 2.7E-04 \\
\hline-0.7 & 7.90 & 3.00E-05 & 0.96 & 11 & 2.04E-05 & 2.2E-04 \\
\hline-0.73 & 8.08 & $3.02 E-05$ & 0.96 & 8 & 2.03E-05 & 1.6E-04 \\
\hline-0.76 & 7.90 & $3.08 \mathrm{E}-05$ & 0.96 & 6 & 2.03E-05 & 1.2E-04 \\
\hline-0.79 & 8.04 & 2.93E-05 & 0.96 & 5 & 2.05E-05 & 1.0E-04 \\
\hline-0.8 & 7.78 & 2.95E-05 & 0.96 & 5 & 2.07E-05 & 9.6E-05 \\
\hline \multicolumn{7}{|c|}{ PANI30/Ni50 -1.85 V } \\
\hline-0.3 & 5.02 & $1.45 \mathrm{E}-03$ & 0.88 & 81 & $6.05 \mathrm{E}-04$ & 4.87E-02 \\
\hline-0.31 & 5.81 & 1.39E-03 & 0.88 & 81 & 5.94E -04 & 4.80E-02 \\
\hline-0.32 & 5.27 & $1.31 E-03$ & 0.89 & 77 & $5.89 E-04$ & 4.54E-02 \\
\hline-0.33 & 5.27 & $1.31 \mathrm{E}-03$ & 0.89 & 77 & $5.89 \mathrm{E}-04$ & 4.54E-02 \\
\hline-0.34 & 6.43 & $1.22 \mathrm{E}-03$ & 0.89 & 65 & $5.91 \mathrm{E}-04$ & $3.86 E-02$ \\
\hline-0.35 & 6.21 & $1.21 \mathrm{E}-03$ & 0.89 & 59 & 5.71E-04 & 3.37E-02 \\
\hline-0.36 & 6.18 & 1.19E-03 & 0.89 & 53 & 5.61E-04 & $2.96 \mathrm{E}-02$ \\
\hline-0.37 & 5.64 & 1.11E-03 & 0.91 & 46 & 5.67E-04 & 2.61E-02 \\
\hline-0.38 & 5.90 & 1.12E-03 & 0.90 & 40 & 5.59E-04 & 2.26E-02 \\
\hline-0.39 & 6.00 & $1.16 \mathrm{E}-03$ & 0.89 & 35 & 5.39E-04 & 1.91E-02 \\
\hline-0.4 & 6.02 & 1.13E-03 & 0.90 & 30 & $5.42 \mathrm{E}-04$ & $1.65 E-02$ \\
\hline-0.41 & 6.10 & $1.12 \mathrm{E}-03$ & 0.90 & 26 & $5.48 \mathrm{E}-04$ & 1.44E-02 \\
\hline-0.42 & 5.99 & $1.10 \mathrm{E}-03$ & 0.90 & 22 & 5.41E-04 & 1.21E-02 \\
\hline-0.43 & 6.08 & $1.15 \mathrm{E}-03$ & 0.89 & 19 & $5.15 E-04$ & 9.96E-03 \\
\hline-0.44 & 5.73 & 1.07E-03 & 0.91 & 16 & 5.41E-04 & 8.87E-03 \\
\hline-0.45 & 6.30 & 1.11E-03 & 0.90 & 14 & $5.29 E-04$ & $7.40 \mathrm{E}-03$ \\
\hline-0.46 & 5.41 & 1.16E-03 & 0.89 & 12 & 5.10E-04 & $6.28 \mathrm{E}-03$ \\
\hline-0.47 & 5.24 & 1.16E-03 & 0.89 & 11 & 4.97E-04 & $5.23 \mathrm{E}-03$ \\
\hline-0.48 & 6.00 & $1.09 E-03$ & 0.90 & 9 & 5.31E-04 & 4.67E-03 \\
\hline-0.49 & 5.33 & 1.27E-03 & 0.87 & 8 & $5.00 \mathrm{E}-04$ & $3.95 E-03$ \\
\hline-0.5 & 5.71 & $1.08 \mathrm{E}-03$ & 0.90 & 7 & 5.30E-04 & $3.45 E-03$ \\
\hline-0.52 & 5.22 & 1.23E-03 & 0.88 & 5 & $5.01 \mathrm{E}-04$ & 2.52E-03 \\
\hline-0.54 & 5.26 & 1.29E-03 & 0.87 & 4 & 4.96E-04 & 1.94E-03 \\
\hline-0.56 & 5.13 & 1.27E-03 & 0.87 & 3 & $4.80 \mathrm{E}-04$ & $1.48 E-03$ \\
\hline-0.58 & 5.20 & $1.18 \mathrm{E}-03$ & 0.89 & 2 & $4.96 \mathrm{E}-04$ & 1.21E-03 \\
\hline-0.6 & 5.04 & $1.43 \mathrm{E}-03$ & 0.86 & 2 & $4.63 \mathrm{E}-04$ & $9.46 E-04$ \\
\hline-0.62 & 5.55 & 1.11E-03 & 0.90 & 2 & $5.26 \mathrm{E}-04$ & 8.51E-04 \\
\hline-0.64 & 5.07 & $1.28 \mathrm{E}-03$ & 0.87 & 1 & 4.66E-04 & 6.77E-04 \\
\hline-0.66 & 4.90 & $1.31 \mathrm{E}-03$ & 0.86 & 1 & 4.35E-04 & 5.69E-04 \\
\hline-0.68 & 4.92 & 1.53E-03 & 0.85 & 1 & $4.28 \mathrm{E}-04$ & 5.01E-04 \\
\hline-0.7 & 5.04 & 1.39E-03 & 0.86 & 1 & 4.43E-04 & 4.44E-04 \\
\hline-0.73 & 5.00 & $1.38 \mathrm{E}-03$ & 0.86 & 1 & $4.40 \mathrm{E}-04$ & 3.70E-04 \\
\hline-0.76 & 5.06 & $1.10 \mathrm{E}-03$ & 0.89 & 1 & $4.41 E-04$ & $3.06 \mathrm{E}-04$ \\
\hline
\end{tabular}


Table A.2 EEC parameters obtained by fitting EIS experimental spectra recorded at various overpotentials on the Ni-RVC and Ni-nanoparticle electrocatalysts.

\begin{tabular}{|c|c|c|c|c|c|c|c|c|c|}
\hline$E$ [V] & $\begin{array}{l}R_{\text {el }} \\
{[\Omega]}\end{array}$ & $\begin{array}{c}\mathrm{CPE}_{1} \\
{\left[\mathrm{mF} \mathrm{cm}^{-2}\right]}\end{array}$ & $\mathrm{n}_{1}$ & $\begin{array}{c}R_{1} \\
{\left[\Omega \mathrm{cm}^{2}\right]}\end{array}$ & $\begin{array}{c}\mathrm{CPE}_{2} \\
{\left[\mathrm{mF} \mathrm{cm}^{-2}\right]}\end{array}$ & $\mathrm{n}_{2}$ & $\begin{array}{c}\mathrm{R}_{2} \\
{\left[\Omega \mathrm{cm}^{2}\right]}\end{array}$ & $\tau_{1}[\mathrm{~ms}]$ & $\tau_{2}[\mathrm{~ms}]$ \\
\hline \multicolumn{10}{|l|}{ Ni-RVC } \\
\hline-0.3 & 1.66 & 3.69 & 0.66 & 0.98 & 11.83 & 0.92 & 24.59 & 0.20 & 232.86 \\
\hline-0.31 & 1.69 & 4.04 & 0.62 & 1.11 & 11.06 & 0.92 & 26.29 & 0.16 & 232.71 \\
\hline-0.32 & 1.67 & 1.55 & 0.69 & 1.47 & 10.62 & 0.93 & 25.69 & 0.14 & 223.56 \\
\hline-0.33 & 1.74 & 3.24 & 0.63 & 1.28 & 10.16 & 0.93 & 25.25 & 0.16 & 206.94 \\
\hline-0.34 & 1.70 & 3.15 & 0.62 & 1.59 & 9.79 & 0.93 & 23.71 & 0.16 & 188.23 \\
\hline-0.35 & 1.72 & 3.91 & 0.63 & 1.14 & 9.59 & 0.93 & 21.45 & 0.17 & 169.08 \\
\hline-0.36 & 1.67 & 2.42 & 0.64 & 1.63 & 9.30 & 0.93 & 20.19 & 0.17 & 152.25 \\
\hline-0.37 & 1.67 & 2.15 & 0.66 & 1.40 & 9.13 & 0.94 & 17.99 & 0.14 & 135.38 \\
\hline-0.38 & 1.71 & 2.78 & 0.63 & 1.40 & 8.94 & 0.94 & 16.47 & 0.14 & 122.01 \\
\hline-0.39 & 1.77 & 5.76 & 0.54 & 1.65 & 8.87 & 0.93 & 15.41 & 0.16 & 111.06 \\
\hline-0.4 & 1.78 & 2.33 & 0.62 & 1.82 & 8.70 & 0.94 & 14.09 & 0.14 & 100.83 \\
\hline-0.41 & 1.76 & 2.17 & 0.60 & 2.26 & 8.67 & 0.92 & 13.53 & 0.13 & 91.46 \\
\hline-0.42 & 1.75 & 2.06 & 0.60 & 2.04 & 8.51 & 0.93 & 12.16 & 0.10 & 81.56 \\
\hline-0.43 & 1.74 & 3.77 & 0.58 & 1.83 & 8.56 & 0.92 & 11.40 & 0.15 & 74.49 \\
\hline-0.44 & 1.73 & 3.74 & 0.59 & 1.75 & 8.43 & 0.92 & 10.51 & 0.16 & 67.11 \\
\hline-0.45 & 1.77 & 3.47 & 0.61 & 1.47 & 8.40 & 0.91 & 9.82 & 0.16 & 60.97 \\
\hline-0.46 & 1.75 & 4.74 & 0.57 & 1.71 & 8.24 & 0.92 & 9.03 & 0.18 & 56.37 \\
\hline-0.47 & 1.77 & 6.24 & 0.55 & 1.85 & 8.21 & 0.93 & 8.19 & 0.27 & 52.19 \\
\hline-0.48 & 1.76 & 4.32 & 0.57 & 1.71 & 8.35 & 0.91 & 7.91 & 0.16 & 48.01 \\
\hline-0.49 & 1.74 & 1.51 & 0.64 & 2.11 & 8.14 & 0.93 & 7.28 & 0.11 & 45.20 \\
\hline-0.5 & 1.73 & 3.41 & 0.55 & 2.79 & 8.05 & 0.95 & 6.59 & 0.17 & 43.75 \\
\hline-0.52 & 1.79 & 1.95 & 0.65 & 1.83 & 8.24 & 0.91 & 6.56 & 0.15 & 38.15 \\
\hline-0.54 & 1.75 & 3.38 & 0.51 & 3.00 & 8.21 & 0.93 & 5.48 & 0.10 & 34.00 \\
\hline-0.56 & 1.75 & 4.08 & 0.50 & 3.14 & 8.28 & 0.94 & 4.59 & 0.13 & 30.40 \\
\hline-0.58 & 1.82 & 0.89 & 0.69 & 1.94 & 8.46 & 0.88 & 4.93 & 0.10 & 25.76 \\
\hline-0.6 & 1.83 & 1.64 & 0.63 & 2.50 & 8.75 & 0.90 & 4.21 & 0.14 & 24.02 \\
\hline-0.62 & 1.83 & 3.09 & 0.58 & 2.00 & 6.82 & 0.92 & 4.21 & 0.13 & 20.62 \\
\hline-0.64 & 1.83 & 3.80 & 0.54 & 3.33 & 8.34 & 1.00 & 2.45 & 0.26 & 20.46 \\
\hline-0.66 & 1.80 & 1.24 & 0.62 & 3.04 & 8.82 & 0.90 & 3.18 & 0.11 & 18.11 \\
\hline \multicolumn{10}{|c|}{ Ni-nanopraticles } \\
\hline & & & & & & & & & 3526.4 \\
\hline-0.34 & 6.05 & 39.79 & 0.76 & 25.85 & 73.65 & 1.00 & 47.88 & 430.80 & $\begin{array}{c}7 \\
1350.7\end{array}$ \\
\hline-0.4 & 6.02 & 34.08 & 0.78 & 25.50 & 110.65 & 0.97 & 11.58 & 379.07 & 1 \\
\hline-0.48 & 6.00 & 221.41 & 0.49 & 0.92 & 11.62 & 0.87 & 10.12 & 24.19 & 150.39 \\
\hline-0.56 & 6.65 & 641.48 & 0.36 & 0.25 & 7.78 & 0.83 & 3.90 & 4.66 & 41.38 \\
\hline
\end{tabular}

